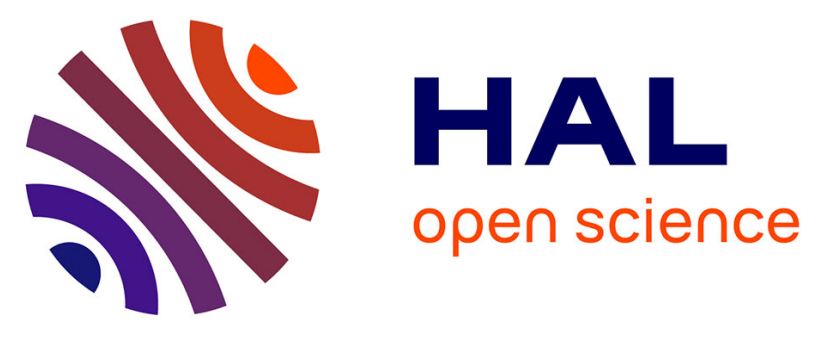

\title{
Salen Complexes as Fire Protective Agents for Thermoplastic Polyurethane: Deep Electron Paramagnetic Resonance Spectroscopy Investigation
}

Anil D. Naik, Serge Bourbigot, Séverine Bellayer, Nadia Touati, Karima Ben Tayeb Meziane, Herve Vezin, Gaelle Fontaine

\section{To cite this version:}

Anil D. Naik, Serge Bourbigot, Séverine Bellayer, Nadia Touati, Karima Ben Tayeb Meziane, et al.. Salen Complexes as Fire Protective Agents for Thermoplastic Polyurethane: Deep Electron Paramagnetic Resonance Spectroscopy Investigation. ACS Applied Materials \& Interfaces, 2018, 10 (29), pp.24860-24875. 10.1021/acsami.8b07323 . hal-02370737

\section{HAL Id: hal-02370737 \\ https://hal.univ-lille.fr/hal-02370737}

Submitted on 19 Nov 2019

HAL is a multi-disciplinary open access archive for the deposit and dissemination of scientific research documents, whether they are published or not. The documents may come from teaching and research institutions in France or abroad, or from public or private research centers.
L'archive ouverte pluridisciplinaire HAL, est destinée au dépôt et à la diffusion de documents scientifiques de niveau recherche, publiés ou non, émanant des établissements d'enseignement et de recherche français ou étrangers, des laboratoires publics ou privés. 


\title{
Salen complexes as fire protective agents for thermoplastic polyurethane: Deep EPR spectroscopy investigation
}

\author{
Anil D. Naik, ${ }^{1}$ Serge Bourbigot ${ }^{1}$, Séverine Bellayer, ${ }^{1}$ Nadia Touati, ${ }^{2}$ Karima Ben Tayeb, ${ }^{2}$ \\ Hervé Vezin, ${ }^{2}$ Gaëlle Fontaine ${ }^{1 *}$ \\ ${ }^{1}$ Univ. Lille, ENSCL, UMR 8207 - UMET - Unité Matériaux et Transformations, F-59652 Villeneuve \\ d'Ascq, France \\ ${ }^{2}$ Univ. Lille, CNRS, UMR 8516 - LASIR - Laboratoire de Spectrochimie Infrarouge et Raman, F-59652 \\ Villeneuve d'Ascq Cedex, France. \\ *Corresponding author: e-mail: gaelle.fontaine@ensc-lille.fr
}

Keywords: Schiff bases, Salen, Copper complex, Thermoplastic polyurethane, Flame retardancy, EPR spectroscopy

\section{Abstract:}

The contribution to flame retard thermoplastic polyurethane (TPU) of Copper complexes of Salen based Schiff bases $N, N^{\prime}$-bis(salicylidene)ethylenediamine (C1), $\quad N, N^{\prime}$-bis(4hydroxysalicylidene)ethylenediamine

and $N, N^{\prime}$-bis $(5-$ hydroxysalicylidene)ethylenediamine (C3) is investigated in the context of minimizing TPU inherent flammability. Thermal and fire properties of TPU are evaluated. It is observed that fire performances vary depending upon the substitution of Salen framework. Cone calorimetry (MLC) results show that, in TPU at $10 \mathrm{wt} .-\%$ loading, C2 and C3 reduce peak of heat release (pHRR) by 46 and 50\% respectively. At high temperature, these copper complexes undergo polycondensation leading to resorcinol type resin in the condensed phase and thus acting as intumescence reinforcing agents. C3 in TPU is particularly interesting since it delays significantly the time to ignition (MLC experiment). In addition, Pyrolysis combustion flow calorimetry (PCFC) shows reduction in HRR curve suggesting its involvement in gas phase action. Structural changes of copper complexes and radical formation during thermal treatment as well as their influence on fire retardancy of TPU in the condensed phase is investigated by spectroscopic studies supported by microscopic and powder diffraction studies. Electron paramagnetic resonance spectroscopy (EPR) was fully used to follow redox changes of $\mathrm{Cu}$ (II) ions as well as radical formation of copper complexes/TPU formulations in their degradation 
pathways. Pulsed EPR technique of Hyperfine Sublevel Correlation Spectroscopy (HYSCORE) reveals evolution of local surrounding of copper and radicals with strong contribution of nitrogen fragments in the degradation products. Further, spin state of radicals were investigated by 2D technique of Phase-inverted Echo-Amplitude detected Nutation (PEANUT) experiment. Two different radicals were detected i.e. one mono carbon radical and an oxygen biradical. Thus, the EPR study permits to deeply investigate the mode of action of copper salen complexes in TPU.

\section{Introduction:}

Inorganic products ${ }^{1}$ occupy major share in the flame retardant (FR) solution package for engineering polymers, ${ }^{1-13}$ elastomers,${ }^{14-15}$ insulation materials/coatings and textiles. ${ }^{16}$ Metals across the periodic table were studied as FR since they can occur in diverse forms (e.g. oxides, hydroxides, carbonates, and other salts) and they can virtually offer unlimited possibilities. Metal bound compounds provide effective flame retardancy by several routes. Their role in FR solution is manifold although their primarily used as a FR additive or a synergist. ${ }^{14}$ They can act in both condensed and gas phases. They are also considered for their role as compatibilizers/processing aid, smoke suppressants, stabilizers, char reinforcing agents, char former, ceramization/glass former, catalyst, and cross-linking agents irrespective of their hierarchical level at their molecular organization. They may have endothermic effect by absorbing heat from combustion zone. Hydrated metal compounds releases water at higher temperature which acts as fuel diluent. In case of magnesium hydroxide $\left(\mathrm{Mg}(\mathrm{OH})_{2}\right)$ the dehydration temperature is superior to $300^{\circ} \mathrm{C}$ which is unusually higher unlike classical hydrated compounds which are normally released around $100-150^{\circ} \mathrm{C}$. Some metal oxides formed during burning migrate and reinforce char surface that can deflect heat and acts as a thermal shield.

Simple metal salts (e.g. $\mathrm{Mg}^{2+}, \mathrm{Al}^{3+}, \mathrm{Ti}^{4+}$, Lanthanides) and oxides are the basis of this database of inorganic functionalities. ${ }^{1-8}$ Salts of higher compositional order/chelates such as metal acetates, acetonates, oxalates, borates, phosphates, phosphinates, double salts (e.g. Alum), are also well known in FR formulations. Next candidates in this level of molecular hierarchy are inorganic-organic hybrid molecules that have emerged as contemporary multi-functional additives. ${ }^{17,18}$ Melamine intercalated metal polyphosphates (e.g. Safire ${ }^{\circledR}$ ) belongs to this category. Coordination compounds or metal complexes were relatively new in this domain of 
FR whose admission was restricted largely due to the misunderstanding of their limited thermal stability. ${ }^{15}$ Silicates, zeolites, organically modified clays were already extensively used in this domain. ${ }^{19,20}$ The other end of this spectrum of molecular hierarchy is tailorable coordination polymers $(\mathrm{CP}) /$ metal-organic frameworks (MOF) which are unexplored in the scope of FR (figure 1). ${ }^{21}$
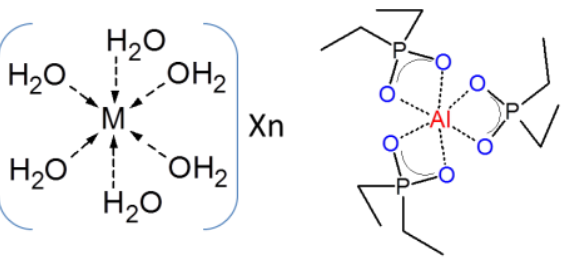

Metal salts

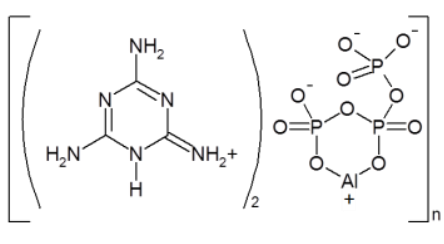

hybrids

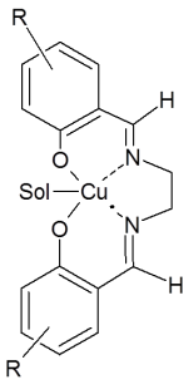

complexes
Zeolites

Silicates

Clay

MOF/CF

Molecular complexicity $\rightarrow$

Figure 1. Tentative classification of inorganic elements used in flame retardancy ( $X=$ anion, $\mathrm{n}=$ number, Sol=solvent, $\mathrm{R}=$ substituant, e.g. hydroxyl group) (MOF: metal-organic frameworks; CP: coordination polymer).

Coordination complexes or simply metal complexes are molecular entities wherein predesigned organic molecules (also called ligands) are allowed to react with metal salts to have topologically diverse molecular architecture combing the properties of both organic and inorganic functionalities. They can offer wide range of tailorability to target application with the help of molecular engineering concept. Their distribution, organization and properties in the host matrix (e.g. polymers) depends on several factors like polarity of molecules, functional groups on the periphery of the molecules, reactivity of metal centers, unsaturation at metal centers, supramolecular interactions, coordination number of metal centers, thermal stability, hydrophobic/philic interactions etc. Metal salts or simple metal chelates have high tendency to form coordinate bonds with wide range of donor atoms of host matrices often changing the physical properties. On the other hand, metal complexes may limit the interaction of metal ions in the host matrix and if their demetallation takes place, their interference with functional groups of matrix is restricted. However, their high temperature applications are still in their infancy.

A recent work by Fontaine et. al on copper complexes based on 'Salen' molecules in the flame retardancy of thermoplastic polyurethane revitalized the concept of 'tailored' metal complexes 
for high temperature protective applications. ${ }^{15}$ Although metal bound additives were extensively used in the flame retardancy of polypropylene, polyethylene, PVC, TPU, epoxy, polyamides, polycarbonates, EVA, PVA, cotton fibers etc. ${ }^{1-14}$ the unique feature about this Salen copper complexes were their simple molecular framework. Mostly such designs were used in molecular sensors, catalysis, and biological applications but been ignored for high temperature applications. ${ }^{22,23}$ In our recent study we have shown how such well-designed organic molecules could undergo in situ structural transformation forming thermally stable resins and improve fire weakness of TPU. ${ }^{22}$

Present work is about elucidating the role of such Salen copper complexes that is an extension of our previous work ${ }^{15}$ in the fire protection of TPU. The reason for choosing TPU is its impressive range of performance characteristics, and high demand for their fire protection requirements to extend their service life in coatings, adhesives, flexible foams and other applications. $^{24,25}$ We have used substituted and un-substituted Salen molecules for complexation with copper salts. Fire performance, thermal properties, characterization of complexes in the TPU matrix and their degradation pathway leading to fire protection are discussed.

\section{Experimental}

\subsection{Materials}

Thermoplastic Polyurethane (TPU) C85A (Elastollan) polyester polyurethane) was kindly supplied by BASF. ${ }^{29}$ Copper complexes of $N, N$ '-bis(salicylidene)ethylenediamine (C1) and $N, N$ '-bis(4-hydroxysalicylidene)ethylenediamine

and

$N, N^{\prime}$-bis $(5-$ hydroxysalicylidene)ethylenediamine (C3) were synthesized based on earlier reports. ${ }^{15}$

\subsection{Formulations, processing, and sampling}

TPU is dried for 12 hours at $80^{\circ} \mathrm{C}$ before use. Compounding of formulations with $10 \mathrm{wt} \%$ of $\mathrm{C} 1, \mathrm{C} 2$ or $\mathrm{C} 3$ were performed using HAAKE Rheomix OS PTW 16 blender. ${ }^{15}$ The temperature of the mixer was set at $180^{\circ} \mathrm{C}$ and the shear was $50 \mathrm{rpm}$ for 10 minutes. These blended mixtures were ground in liquid nitrogen in an ultracentrifuge mill to produce a powder and dried at 80 ${ }^{\circ} \mathrm{C}$ under vacuum for $12 \mathrm{~h}$ before use.

Samples for elucidating fire protection and decomposition pathways were mainly obtained from thermogravimetric studies (TGA) wherein TGA at the end of each degradation step was stopped and sample were collected. Samples were also collected from cone calorimetry 
experiment which is based on HRR (heat release rate) curve wherein sample (100 x $100 \times 3$ $\mathrm{mm}^{3}$ plates) exposure to heat flux were stopped and withdrawn at the onset, peak, descending, and end of HRR curve. Onset, peak and residue in the manuscript means degradation samples collected at the beginning, peak and end of the MLC experiment. A $4 \times 4 \mathrm{~cm}$ piece is scooped out from the central part of these plates including the intumescence part. Residue are manually crushed and collected. Other samples are semi-solid and are cut into small pieces and ground in liquid nitrogen in an ultracentrifuge mill to produce a powder. Samples were dried at $100{ }^{\circ} \mathrm{C}$ under vacuum for $12 \mathrm{~h}$ and stored. These samples are used for some analysis.

\subsection{Instrumental}

\subsubsection{Thermal analysis:}

Thermogravimetric analyses (TGA) were performed using SDT Q600 (TA instruments). Samples (approx. 6-7 mg) were placed in open alumina pans and heated under nitrogen atmosphere $(100 \mathrm{~mL} / \mathrm{min})$ with a heating rate of $10^{\circ} \mathrm{C} / \mathrm{min}$.

\subsubsection{Mass loss cone calorimeter:}

The mass loss cone calorimeter (Fire Testing Technology (FTT), ISO 13927, ASTM E906) is used for recording heat release rate (HRR) curve. Plates $\left(100 \times 100 \times 3 \mathrm{~mm}^{3}\right.$ plates) for cone calorimeter test were made via compression molding using DARRAGON press apparatus (50 $\mathrm{kN}, 6 \min , 185^{\circ} \mathrm{C}$ ). Plates were wrapped in aluminium foil leaving the upper surface exposed to the heater and placed in horizontal position on ceramic block encased in a metallic container at a distance of $35 \mathrm{~mm}$ from cone base. External heat flux of $35 \mathrm{~kW} / \mathrm{m}^{2}$ was used for all the experiments. The experiments were done in triplicate and the error on the measured parameters is within $10 \%$.

\subsubsection{Pyrolysis combustion flow calorimetry (PCFC):}

Fire performance was evaluated based on heat release rate (HRR) curve obtained from FAA Micro calorimeter (FAA Fire testing technology) operated at $1{ }^{\circ} \mathrm{C} / \mathrm{s}$ to $700^{\circ} \mathrm{C}$ in the pyrolysis zone according to ASTM D7309-07 method A. The combustion zone was set at $900^{\circ} \mathrm{C}$. Oxygen and nitrogen flow rates were set at 20 and $80 \mathrm{cc} / \mathrm{min}$ respectively. Repeatability is confirmed by three consecutive trials. 


\subsubsection{Spectral and microscopy analysis:}

FT-IR were recorded on Nicolet iS 50 in ATR mode at room temperature. VHX digital optical microscope (Keyence, VH-Z 100R) was used to investigate texture of samples. The surface of the sample for EPMA was prepared with a Leica Ultracut ultramicrotome at cryo temperature with a diatome diamond knife. The images were taken with a Cameca SX100 EPMA in BSE mode at $15 \mathrm{kV} 15 \mathrm{nA}$. Morphology of char and some residues were studied using scanning electron microscope (SEM) (Field emission gun (FEG) Hitachi S4700).

CW EPR/Pulsed EPR: EPR continuous-wave (CW) experiments were performed on X-Band Bruker ELEXSYS E500 spectrometer operating at $9.78 \mathrm{GHz}$. The powder was inserted in quartz tube and the spectra were recorded on TM cavity at room temperature under nonsaturated conditions: microwave power in a range of 1-12 $\mathrm{mW}$ and modulation amplitude in a range of 2-6 G. High temperature experiments were recorded on ER4114HT cavity which was purged by nitrogen. The powder was inserted in Tailor-made sample tubes. The temperature was measured with a thermocouple (type $\mathrm{K}$ : $\mathrm{Cr}-\mathrm{Al}$ ) close to the sample. The gas flow rate and the temperature are controlled with the temperature unit (ER 4131VT). The heating thermal power is provided by the power booster ER4131VT-1020.

Pulsed EPR was studied at 5K with a Bruker ELEXSYS E580 spectrometer equipped with a helium flow cryostat. 2-pulses echo field sweep acquisitions were performed using standard Hahn echo sequence $90-\tau-180$ - with $90^{\circ}$ pulse length of 16 ns and $\tau$ value of $136 \mathrm{~ns}$. The HYperfine Sublevel CORrElation spectroscopy (HYSCORE) ${ }^{26}$ experiments were recorded with $256 \times 256$ data points for both $\mathrm{t} 1$ and $\mathrm{t} 2$ time domains, $90^{\circ}$ pulse length of 10 or $24 \mathrm{~ns}$ (respectively for copper and radicals) and an echo delay of $136 \mathrm{~ns}$. The obtained HYSCORE spectra are composed of two quadrants: the first quadrant $(+,-)$ where $A>2 v_{I}$ ( $v_{I}$ being the nuclear frequency) corresponding to strong hyperfine coupling A between the I nucleus and the unpaired electron and the second quadrant $(+,+)$ where $A<2 v_{\text {I }}$ corresponding weaker interactions. Direct measurement of the spin (S) was performed by Phase-inverted EchoAmplitude detected Nutation (PEANUT) experiment ${ }^{27}$ using a two dimensional versus field sweep. The non-selective $\pi / 2$ preparation pulse of length tp of $16 \mathrm{~ns}$ was performed with two steps phase cycling $(+\mathrm{X},-\mathrm{X})$. The spectrum was recorded with $256 \times 256$ data points along both dimensions, $90^{\circ}$ pulse length of $16 \mathrm{~ns}$ separated from the nutation pulse by the time interval of $136 \mathrm{~ns}$. Spectra are recorded at $5 \mathrm{~K}$. 


\subsubsection{TGA-FTIR analysis:}

Gas phase analysis were carried out in TGA Q5000 (TA instruments) coupled with FTIR Nicolet spectrometer (ThermoFischer). Samples $(\sim 10 \mathrm{mg})$ were heated in a $250 \mu \mathrm{L}$ alumina crucible from $50^{\circ} \mathrm{C}$ to $800^{\circ} \mathrm{C}$ with a heating rate of $10^{\circ} \mathrm{C} / \mathrm{min}$ under nitrogen atmosphere. A balance purge flow of $15 \mathrm{~mL} / \mathrm{min}$ and a sample purge flow of $100 \mathrm{~mL} / \mathrm{min}$ was maintained. A transfer line with an inner diameter of $1 \mathrm{~mm}$ was used to connect TGA and infrared cell. The temperature of transfer line and gas cell was kept at $225^{\circ} \mathrm{C}$. Prior to this, samples were kept for $2 \mathrm{~h}$ under nitrogen stream. IR spectra were collected in $400-4000 \mathrm{~cm}^{-1}$ spectral range.

\subsubsection{Pyrolysis GC/MS:}

Samples ( 200 $\mu \mathrm{g}$ ) were analyzed by Pyrolysis GC/MS (Shimadzu, GCMS-QP2010 SE). GC separation was carried out with a fused silica capillary column (SLB 5ms) of 30m length and $0.25 \mu \mathrm{m}$ thickness. Analyses were carried out both in direct pyrolysis mode and desorption method. The temperature selection for desorption is based TGA pattern of concerned sample with a heating rate of $10^{\circ} \mathrm{C} / \mathrm{min}$. The initial column temperature was held at $35^{\circ} \mathrm{C}$ for a period that corresponds to desorption time followed by a temperature ramp at $10^{\circ} \mathrm{C} / \mathrm{min}$ to a final temperature of $300{ }^{\circ} \mathrm{C}$ and isotherm for $20 \mathrm{~min}$. For direct pyrolysis the furnace is set for the final temperature $\left(600^{\circ} \mathrm{C}\right.$ which corresponds to completion of second major degradation step) and sample is pyrolysed for $0.5 \mathrm{~min}$. Column oven temperature is programmed in the following way. The initial column temperature was held at $35{ }^{\circ} \mathrm{C}$ for $1 \mathrm{~min}$. followed by a temperature ramp at $10^{\circ} \mathrm{C} / \mathrm{min}$ to a final temperature of $300^{\circ} \mathrm{C}$ and isotherm for $20 \mathrm{~min}$. Helium was used as a carrier gas at pressure of $120 \mathrm{kPa}$ with a split ratio of 50 . The transfer line was maintained at $275^{\circ} \mathrm{C}$. The MS was operated under Electron Ionization EI mode. An online computer using GCMS real time analysis and PY-2020i software controlled GC/MS system. The eluted components were identified by library search and only significant peaks (above 90\% match) observed in the total ion chromatograms were studied and compared to a mass spectral database (GCMS postrun analysis, and NIST).

\section{Results and discussion}

\subsection{Fire performances}

Flammability characteristic of TPU and flame retarded formulations (with 10wt \% of C1-C3) are evaluated from heat release rate (HRR) curves derived from two different techniques - 
Mass loss calorimetry (MLC) and Pyrolysis combustion flow calorimetry (PCFC). They are displayed in Figure 2a and $2 \mathrm{~b}$ and parameters are given in Table 1.
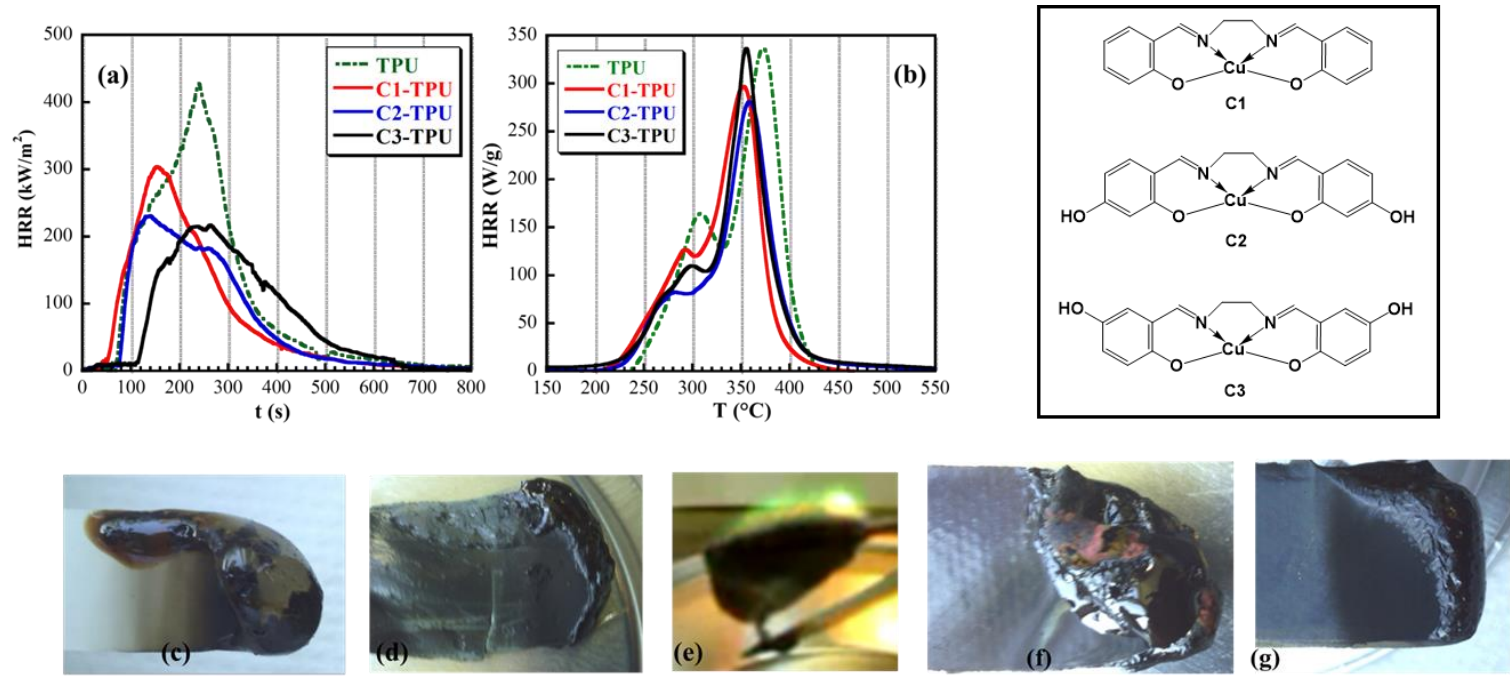

Figure 2. (a) HRR curve obtained from mass cone calorimetry. (b) HRR curve obtained from PCFC. (c, d, f, g) Response to flaming under LOI condition (c) neat TPU (d) C1-TPU (e) A piece of C1-TPU burning with green flame (f) Intumescence in C2-TPU also showing red patches (g) Slight intumescence in C3-TPU.

Neat TPU under cone calorimetry conditions burns almost totally resulting in small amount of brittle char (pHRR, $426 \mathrm{~kW} / \mathrm{m}^{2}$ ). C1-TPU shows $30 \%$ reduction in pHRR and C2-TPU shows $46 \%$ reduction of the pHRR with a shoulder on the pHRR. C3-TPU exhibits the best behaviour with nearly $50 \%$ reduction in pHRR and stretches the ignition (sustain) for longer time (110s vs. $65 \mathrm{~s}$ for neat TPU). Total heat release (THR) for TPU is $83.8 \mathrm{MJ} / \mathrm{m}^{2}$ and decreases to 60.9 $\mathrm{MJ} / \mathrm{m}^{2}$ for $\mathrm{C} 1$ and is nearly in the same range for C2-TPU and C3-TPU i.e. $56.8 \mathrm{MJ} / \mathrm{m}^{2}$ and $59.5 \mathrm{MJ} / \mathrm{m}^{2}$ respectively (Table 1). Unlike TPU, C1-TPU and C2-TPU time to ignition (TTI) for C3-TPU is highest with 110s against values range of 65-75 s. PCFC of neat TPU shows two peaks with the first one whose being smaller. Both peaks are slightly reduced in the case of C1-TPU formulation. Interestingly C2-TPU shows reduction in HRR in both peaks that is considerable in the first step (50\% reduction in pHRR) compared to $\mathrm{C} 1$ and $\mathrm{C} 3$. C3-TPU does not show significant reduction in these values. In all the formulations, both signals are slightly shifted to lower temperature. LOI test did not show any improvement, the LOI values range is 23-24 vol-\% (Table 1). While C1-TPU displays dripping, C2-TPU shows intumescence whereas C3-TPU shows both dripping and intumescence (Figure 2). 
Table 1. Fire properties derived from mass loss calorimeter, PCFC and LOI for TPU and formulations.

\begin{tabular}{c|c|c|c|c|c|c}
\hline \multirow{2}{*}{ Materials } & \multicolumn{2}{|c|}{ Mass loss calorimeter parameters } & \multicolumn{2}{|c|}{ PCFC parameters } & $\begin{array}{c}\text { LOI } \\
(\%)\end{array}$ \\
\cline { 2 - 7 } & $\begin{array}{c}\text { Time } \\
\text { to ignition } \\
(\mathrm{s})\end{array}$ & $\begin{array}{c}\mathrm{pHRR} \\
\left(\mathrm{kW} / \mathrm{m}^{2}\right)\end{array}$ & $\begin{array}{c}\mathrm{THR} \\
\left(\mathrm{MJ} / \mathrm{m}^{2}\right)\end{array}$ & $\begin{array}{c}\mathrm{pHRR} \\
(\mathrm{W} / \mathrm{g})\end{array}$ & $\begin{array}{c}\mathrm{THR} \\
(\mathrm{kJ} / \mathrm{g})\end{array}$ & \\
\hline TPU & 65 & 426 & 83.8 & 164,336 & 25.7 & 23 \\
\hline $\mathrm{C} 1-\mathrm{TPU}$ & 50 & $300(-30 \%)$ & $60.9(-27 \%)$ & 126,295 & 22.8 & 23 \\
\hline $\mathrm{C} 2-\mathrm{TPU}$ & 75 & $229(-46 \%)$ & $56.8(-32 \%)$ & 81,280 & 20.9 & 23 \\
\hline $\mathrm{C} 3-\mathrm{TPU}$ & 110 & $217(-49 \%)$ & $59.5(-29 \%)$ & $77,110,335$ & 22.6 & 24 \\
\hline
\end{tabular}

In the following sections each complex is discussed separately focussing their thermal properties, distribution in TPU matrix and their possible role in thermal protection.

\subsection{Case study of C1-TPU \\ 3.2.1. C1 in TPU matrix}

$\mathrm{C} 1$ is a green microcrystalline solid and upon blending in TPU imparts green colour to the TPU. Reported three-dimensional X-ray methods shows that $\mathrm{C} 1$ is a four coordinate, mononuclear complex and the geometry varies with solvent of crystallization. ${ }^{28}$ A section in supplementary information is dedicated to the preliminary characterisation and thermal properties of C1 (Figure S1-S4). BSE image and elemental mapping (Figure 3) by EPMA studies have shown that $\mathrm{C} 1$ was uniformly distributed in TPU matrix.

(a)
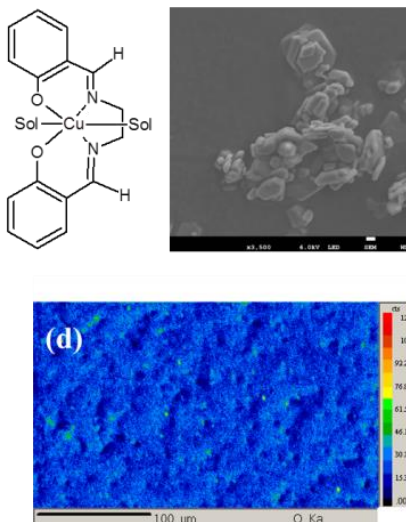

(b)
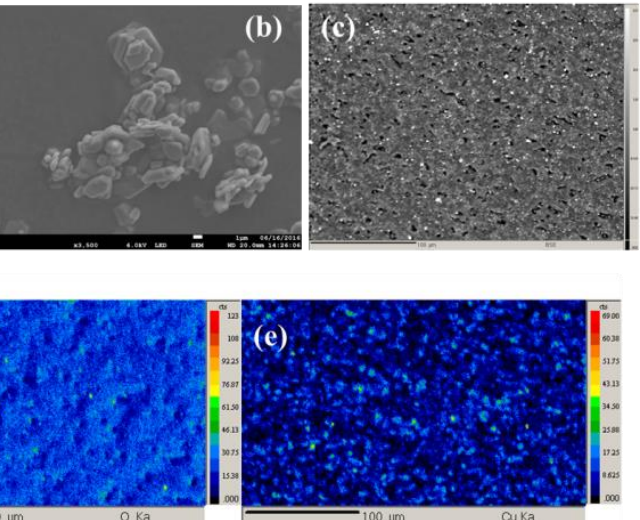

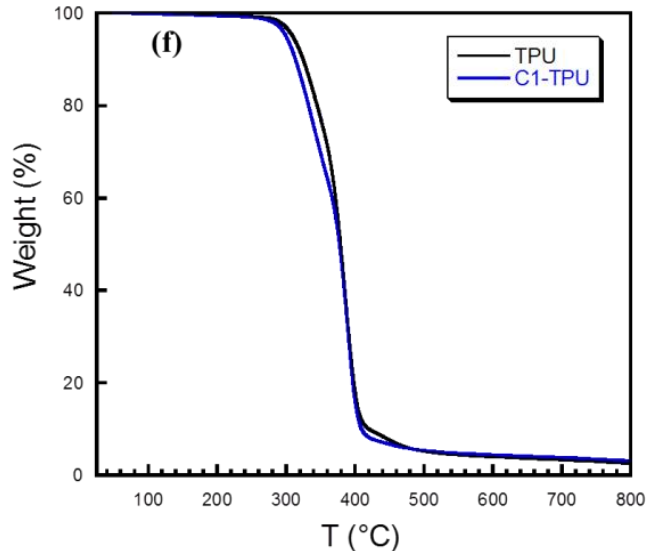

Figure 3. (a) Tentative molecular structure of C1. (b) Microscopic image on C1. (c) BSE image on C1-TPU. (d,e) Elemental mapping (oxygen and copper respectively) by EPMA showing distribution of $\mathrm{C} 1$ in C1-TPU. (f) TGA of TPU and C1-TPU (under nitrogen atmosphere and $\left.10^{\circ} \mathrm{C} / \mathrm{min}\right)$. 
By comparing FTIR of C1-TPU (Figure S4) and neat TPU it is found that none of the TPU signals are affected $\left(v(\mathrm{NH})\left(3331,3305 \mathrm{~cm}^{-1}\right.\right.$ doublet) and $v(\mathrm{CH})$ signal (sharp signals at 2922 and $\left.2852 \mathrm{~cm}^{-1}\right)$ ). The $1704 \mathrm{~cm}^{-1}$ band due to $-\mathrm{C}=\mathrm{O}$ stretching vibration of urethane and $-\mathrm{C}=\mathrm{O}$ stretch of polyol signal at $1727 \mathrm{~cm}^{-1}$ are also unaffected. ${ }^{30-33}$ When compared to $\mathrm{C} 1$ additional signals are observed corresponding to main characteristic bands of $\mathrm{C} 1$.

\subsubsection{Thermal degradation and associated structural changes}

In TGA studies (Figure 3f, Table 2) it is found that neat TPU begin to lose weight slowly above $250^{\circ} \mathrm{C}$. Although there is no clear distinction between decomposition steps, weight loss in the first step is gradual until $360^{\circ} \mathrm{C}$ and thereafter is more pronounced until $430^{\circ} \mathrm{C}$. Small amount of residue is left after $500^{\circ} \mathrm{C}$ (i.e. $2.5 \%$ at $800^{\circ} \mathrm{C}$ ).

Table 2. Thermal properties of TPU and formulations (under nitrogen atmosphere and $\left.10^{\circ} \mathrm{C} / \mathrm{min}\right)$.

\begin{tabular}{c|c|c|c}
\hline Material & $\begin{array}{c}\left.\text { 1st step (T, }{ }^{\circ} \mathbf{C}\right) \\
(\text { weight loss, } \%)\end{array}$ & $\begin{array}{c}\mathbf{2}^{\text {nd }} \text { step }\left(\mathbf{T},{ }^{\circ} \mathbf{C}\right) \\
(\text { weight loss, } \%)\end{array}$ & $\begin{array}{c}\text { Residue } \\
\text { at } \mathbf{5 0 0}^{\circ} \mathbf{C}\end{array}$ \\
\hline TPU & $\begin{array}{c}50-350 \\
(22.5)\end{array}$ & $\begin{array}{c}350-430 \\
(68.3)\end{array}$ & 2.9 \\
\hline C1-TPU & $\begin{array}{c}50-357 \\
(34.4)\end{array}$ & $\begin{array}{c}357-429 \\
(58 \%)\end{array}$ & 3.1 \\
\hline C2-TPU & $\begin{array}{c}50-339 \\
(16.2)\end{array}$ & $\begin{array}{c}339-463 \\
(68.4)\end{array}$ & 10.5 \\
\hline C3-TPU & $\begin{array}{c}50-359 \\
(25.1)\end{array}$ & $\begin{array}{c}359-443 \\
(59.7)\end{array}$ & 9.0 \\
\hline
\end{tabular}

TG curve of neat $\mathbf{C 1}$ shows that it is stable until $323^{\circ} \mathrm{C}$ that is quite high for a Schiff base complex (Figure S1). Decomposition curve of C1-TPU took deviation quite early in the first gradual step (compared to TPU) indicating a slight destabilising effect but behaves much similarly to TPU in the second step and also in terms of residue (3.1\%). The residue amount indicates that $\mathrm{C} 1$ could not bring out significant changes to promote char formation (as also seen in LOI experiment).

Samples at the end of first stage of decomposition is collected and analysed by FTIR. C1-TPU358 (sample collected at $358^{\circ} \mathrm{C}$ from TGA experiment) which represents the end of the first step of decomposition shows that $3346 \mathrm{~cm}^{-1}$ band due to $-\mathrm{NH}$ disappears. $1704 \mathrm{~cm}^{-1}$ band due 
to $-\mathrm{C}=\mathrm{O}$ stretching vibration of urethane is reduced that indicates breakdown of urethane group. However, the $-\mathrm{C}=\mathrm{O}$ stretch of polyol signal $\left(1727 \mathrm{~cm}^{-1}\right)$ is unaffected. These changes were also observed in the degradation of neat TPU. Along with this, band at $1528 \mathrm{~cm}^{-1}$ (semicircle aromatic stretch) decreases in intensity and $1223 \mathrm{~cm}^{-1}$ signal due to $-\mathrm{C}-\mathrm{O}$ stretch is disappeared. If we compare FTIR of TPU-348 and C1-TPU-358, we can see that additional bands are observed at $1617,1572,757 \mathrm{~cm}^{-1}$ which indicates formation of some new aromatic structure (Figure S5). No further analysis was done on small amount of char at the end of analysis.

DSC profile of C1-TPU is much similar to TPU (Table S2) with broad endothermic signal around $175^{\circ} \mathrm{C}$ due to disordering of hard segment (HS) crystallites and at $214^{\circ} \mathrm{C}$ corresponds to melting of HS of TPU. In the cooling mode an exothermic peak is observed $\left(83^{\circ} \mathrm{C}\right)$ due to crystallization.

\subsubsection{Discussion on C1 Performances in TPU}

Based on the above results and on structural changes upon thermal treatment the effect of the $\mathrm{C} 1$ copper complexe on fire retardancy of TPU is followed. This is mostly focussed on the analysis of residues of C1-TPU formulation collected either from TGA or from MLC experiment. The aromatic species found in the residue of C1-TPU-358 is from degrading fragments of $\mathrm{C} 1$, possibly containing phenolic group bonded to copper. But this new aromatic species could not promote a strong char formation and is unable to hold the molten polymer. Under MLC condition, before ignition it is observed that C1-TPU initially displays weak intumescence, which soon collapse. Interestingly during cone test flames were imparted with green colour. It is due to some part of sublimation of complex (or free copper ions from Salen framework after de-metallation) and subsequent atomisation of copper ions that gives characteristic green colour to the flame. Thus significant amount of copper ions are lost and possible action of $\mathrm{C} 1$ in condensed phase is lost. During py-GC/MS experiments (on $\mathrm{C} 1$ ) sublimation of Salen ligand is detected that shows that ligand part is dissociated from copper ions during the thermal treatment and escapes as volatiles (although its detection is below the expected level in py-GC/MS of C1-TPU). Further, no additional char is observed from TGA. Thus there is no significant contribution of $\mathrm{C} 1$ or copper in the condensed phase. PCFC results show little reduction of the pHRR and THR, therefore $\mathrm{C} 1$ present a little contribution in the gas phase. The observed reduction in MLC it is maybe also due to small amount of char swelled by volatiles accompanied. 


\subsection{Case study of C2-TPU}

\subsubsection{C2 in TPU matrix}

Regarding the MLC test, it appears that the reduction's peak HRR (46\%) is more significant in C2-TPU than its non-hydroxy analogue (C1) making it worth to explore in detail. C2-TPU is a violet microcrystalline solid. EPMA shows the distribution of additives in the TPU matrix (Figure 4b-d). Due to large particle size, dispersion seems to be less than for C1-TPU. TPU matrix seems to be unaffected by the insertion of C2 in TPU as shown by FTIR (comparison of C2-TPU and C2, Figure S6). The band at $1620 \mathrm{~cm}^{-1}$ in $\mathrm{C} 2$ is clearly seen in C2-TPU but most of other signals are overlapped. The $v(\mathrm{OH})$ of $\mathrm{C} 2$ at $3442 \mathrm{~cm}^{-1}$ is not seen which may be due to its involvement in hydrogen bonding with the matrix. Another possibility is the structural changes of C2 upon insertion in TPU matrix. This could be due to loss of coordinated and nocoordinated water molecules. This is highly probable because the processing temperature of $\mathrm{C} 2$ in TPU is around $180^{\circ} \mathrm{C}$ which is high enough to remove the solvent molecules. It can also be confirmed by TGA of neat C2 (Figure S1) which display small initial weight loss step until $100^{\circ} \mathrm{C}$. Further structural characterization of C2-TPU by solid state NMR as we reported for Salen-TPU ${ }^{22}$ was not possible due to presence of paramagnetic metal ions. However, a complementary technique of Electron Paramagnetic Resonance spectroscopy (EPR) was used to explore structural and electronic changes due to copper ions in C2. To confirm the redox state of the copper, continuous wave-EPR experiments were performed on C2 and C2-TPU collected after thermal treatment. Spectra of C2 and C2-TPU presented in figure 4e, display a broad signal attributable copper (II) $\left(\mathrm{d}^{9}, \mathrm{~S}=1 / 2\right)$ state. The different ' $\mathrm{g}$ ' factor values obtained and line-shapes are significantly different which suggest the changes of copper coordination after insertion in TPU matrix as it was observed by FTIR.

\subsubsection{Thermal degradation and associated structural changes}

Thermal stability of C2-TPU is different from that of C1-TPU (Figure 4f). It begins to lose weight around $263^{\circ} \mathrm{C}$ similarly to neat TPU. The first step of decomposition until $341^{\circ} \mathrm{C}$ is less gradual than neat TPU. The second step is shorter than the TPU one with higher residue weight at the end of the step. Residue weight at $500^{\circ} \mathrm{C}(11.5 \%)$ is quite significant compared to neat C1-TPU (3.1\%). 
(a)

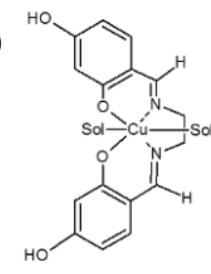

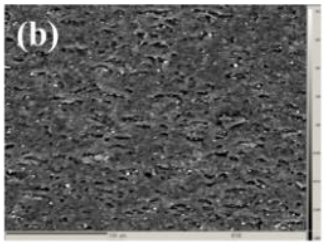

C2-neat

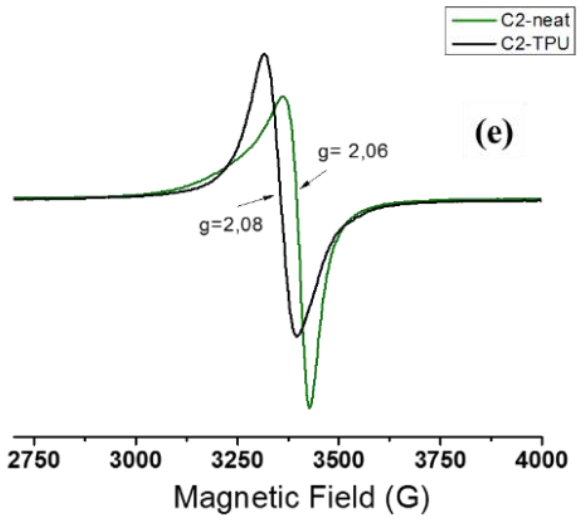

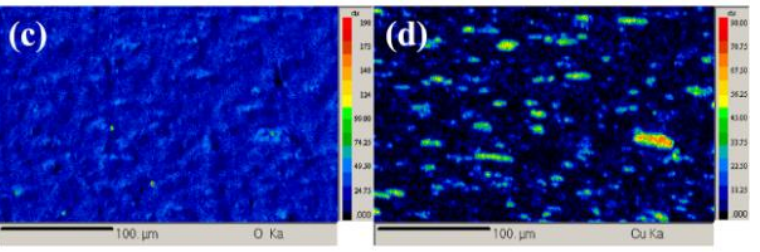

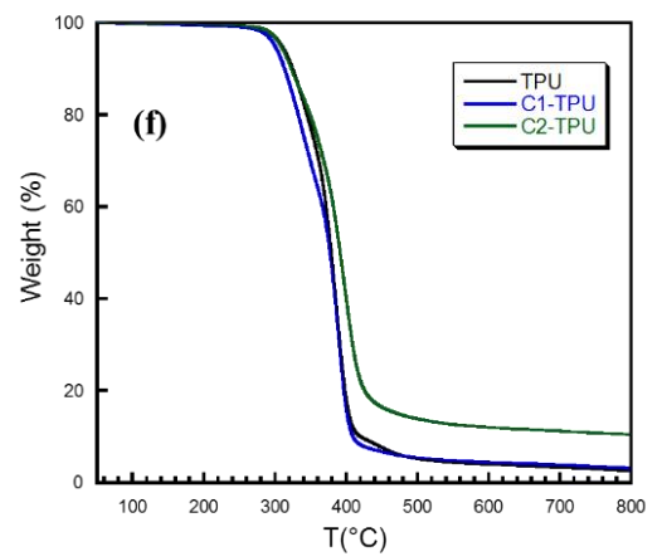

Figure 4. (a) Tentative structural formula of C2. (b) BSE image on C2-TPU (c, d) oxygen and copper mapping respectively in C2-TPU. (e) CW-EPR spectra on neat C2 and C2-TPU. (f) TGA of TPU, C1-TPU and C2-TPU (nitrogen atmosphere, $10^{\circ} \mathrm{C} / \mathrm{min}$ ).

Thermal degradation investigation of C2-TPU is based on sample collected from TGA. TGA was stopped at the end of each degradation step (Table 2) and samples were analysed by FTIR. C2-TPU loses weight $(16 \%)$ until $341^{\circ} \mathrm{C}$ which constitutes first major weight loss step. Analysis on the residue shows that in C2-TPU-341 (which is a stage after initial minor weight loss step) the band of urethane $\left(\mathrm{v}(\mathrm{C}=\mathrm{O})\right.$ has disappeared, and $\mathrm{NH}$ stretch $\left(3349 \mathrm{~cm}^{-1}\right)$ decreased also in intensity. This denotes break down of TPU chain. The band at $1619 \mathrm{~cm}^{-1}$ due to imine in $\mathrm{C} 2$ also decreases. It is also observed a decrease of aromatic stretch at $1532 \mathrm{~cm}^{-1}$ and-C-O stretch at $1220 \mathrm{~cm}^{-1}$ in $\mathrm{C} 2$. This means that $\mathrm{C} 2$ has undergone structural changes during the first TGA degradation step. The degradation product of the first step of decomposition was analysed by TGA-FTIR. From $255^{\circ} \mathrm{C}$ (onset of 1 st decomposition) hydrocarbon fragments, $\mathrm{CO}_{2}$, isocyanate (weak signals) are detected. Around $268^{\circ} \mathrm{C}$, the evolution of hydrocarbon $\left(2998,2874 \mathrm{~cm}^{-1}\right)$, small amount of $\mathrm{CO}_{2}\left(2371,2308,670 \mathrm{~cm}^{-1}\right)$, species containing-C-OH and C-O-C group (1079, $912 \mathrm{~cm}^{-1}$ ) and hydroxyl species (bands above $3594 \mathrm{~cm}^{-1}$ ) are observed. Based on the reported data and as seen in neat TPU this latter product is assigned to butanediol which is also confirmed from py-GC/MS test (Table S3). Second step of decomposition runs between 341 to $463^{\circ} \mathrm{C}$. TGA-FTIR shows that until end of second step of decomposition large 
quantity of hydrocarbon, ketone $\left(1766 \mathrm{~cm}^{-1}\right)$ and small quantity of $\mathrm{CO}_{2}$, and other ester fragments of TPU $\left(1417,1142,1070,922 \mathrm{~cm}^{-1}\right)$ are detected.

Residue left after the second step is analysed by FTIR (Figure 5). C2-TPU-397, which is end of decomposition, shows several spectral changes. There are several additional bands around $1511,1600-1665 \mathrm{~cm}^{-1}$ region characteristic of aromatic species. This corresponds to new substituted aromatic species or aromatic groups from degrading TPU matrix. The residue remaining in TPU at $400^{\circ} \mathrm{C}$ is $~ 5 \%$ whereas it is $14 \%$ in C2-TPU that shows significant amount of char formation. We have seen from MLC that C2-TPU witness intumescence during fire test (Figure S9) and also during LOI. Regarding MLC experiment, this residue formation in the form of char could help to reduce the pHRR and moreover, unlike other samples, C2-TPU behaviour is shared over two bands in HRR curve. ${ }^{34 \mathrm{~b}}$

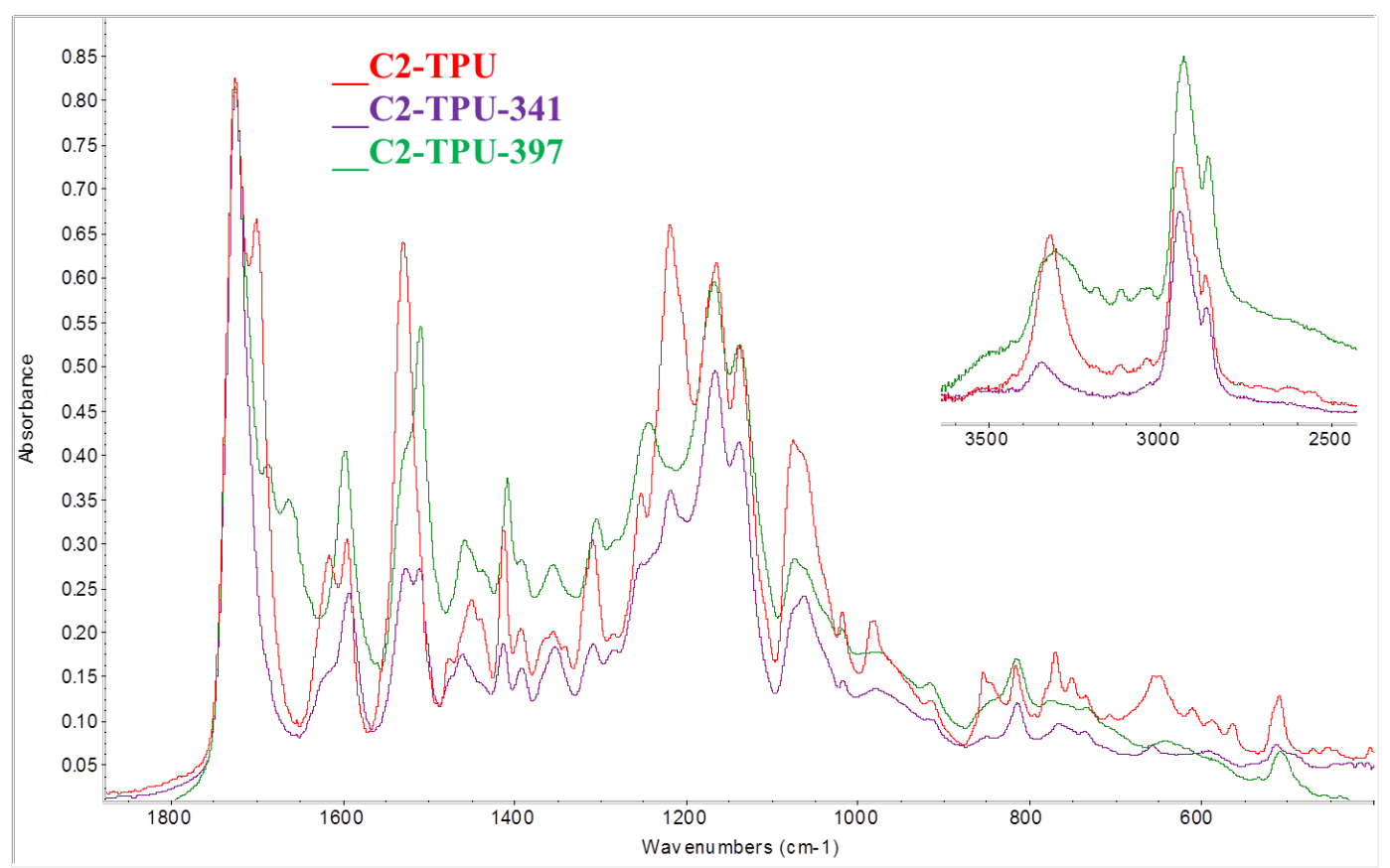

Figure 5. Tracking structural changes of C2-TPU formulation by FTIR

It is also found that neat C2 also produce significant amount of residue (46\%) in TGA analysis at $500^{\circ} \mathrm{C}($ Section $\mathrm{S} 1)$.

\subsubsection{Discussion on $\mathrm{C} 2$ performances in TPU}

Considering the potential of undergoing resin formation of its precursor (L2) ${ }^{22,23}$ the higher residue weight found in $\mathrm{C} 2$ hints to some sort of structural transformation leading to stable 
polymeric structure, promoting char. Temperature treatment in C2 although does not lead to complete turnover to phenolic/resorcinol resin type material as seen in L2, there is an evidence of structural transformation promoting char formation. ${ }^{31}$ After initial thermochromic switch (Figure S7) in $\mathrm{C} 2$ the degradation after $400^{\circ} \mathrm{C}$ is very gradual and extends until $800^{\circ} \mathrm{C}$ (Figure $\mathrm{S} 1)$. This process of poly-condensation and resin formation is also expected during C2-TPU degradation. However, this process gets complicated due to the presence of copper ions and its structural and redox chemistry. This will be tedious to follow in TPU due to the interference from degrading macromolecules and its tendency to unzipping in multiple way at higher temperature. There is evidence from FTIR that some TPU fragments are retained in the residue and thus being a source for char formation. It is possible that char formation have contribution from deviation in unzipping TPU matrix influenced by $\mathrm{C} 2$ and also structural transformation of C2 during thermal treatment. Thus, C2-TPU works mainly by char formation.

\subsection{Case study of C3-TPU:}

C3-TPU shows flame retardancy by intumescence that is slightly different from C2-TPU. This intumescent char is soft and flexible and develops from highly viscous molten intermediate. The significant reduction in pHRR with delayed time to ignition makes C3 a flame retardant for TPU. Under LOI condition, a slight intumescence is observed and the molten state also contributes in the form of dripping

\subsubsection{C3 in TPU matrix:}

C3 is brownish yellow crystalline (Figure 6e) compound that imparts beige colour to C3-TPU. EPMA (Figure 6f) shows the distribution of C3 in TPU matrix, unlike C2, bigger particles or aggregates of complex are observed in the matrix. TPU matrix seems to be unaffected by the copper complex as evidenced by FTIR of C3-TPU (Figure S10). However, the IR bands attributed to $\mathrm{C} 3$ have undergone some changes. Upon insertion into TPU, the broad band at $3164 \mathrm{~cm}^{-1}$ due to $-\mathrm{OH}$ is not seen in C3-TPU that is due to its involvement in hydrogen bonding with the matrix. The $v(\mathrm{C}=\mathrm{N})$ and aromatic ring stretches in $\mathrm{C} 3\left(1634 \mathrm{~cm}^{-1} \mathrm{~s} \mathrm{br}, 1613 \mathrm{~cm}^{-1} \mathrm{sh}\right.$, $1547 \mathrm{~cm}^{-1} \mathrm{~s}, 1472 \mathrm{~cm}^{-1} \mathrm{~m}$ ) are also slightly shifted and appeared with lower intensity. The phenolic $v(\mathrm{CO})$ that appears at $1267 \mathrm{~cm}^{-1}$ and $1159 \mathrm{~cm}^{-1}$ in $\mathrm{C} 3$ is seen but with lower intensity. This suggest that C3 upon distribution TPU matrix did not retain its original geometry. This is due to loss of coordinated water molecules during the processing with TPU that changes the geometry around copper and re-alignment of hydrogen bonding with the matrix. This is further supported by the change in EPR signal of C3 in C3-TPU (figure 6b and c). As observed on C2TPU samples, CW-EPR study on C3 and C3-TPU powders indicates changes in molecular 
environment around copper (figure $6 \mathrm{~b}$ and $\mathrm{c}$ ). Indeed at room temperature, $\mathrm{C} 3$ present a signal of Copper (II) state with an axial symmetry $\left(\mathrm{g}_{/ /}=2.18\right.$ and $\left.\mathrm{g}_{\perp}=2.08\right)$ whereas C3-TPU display a broad signal centered at 'g' value of 2.07 .

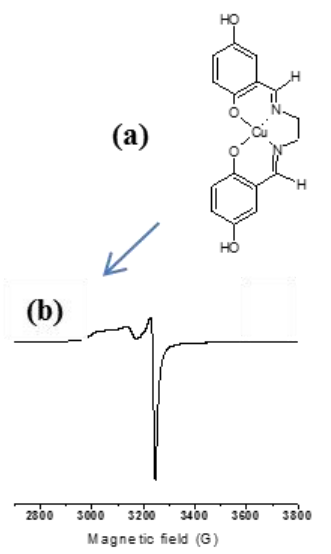

(e)

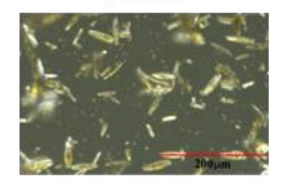

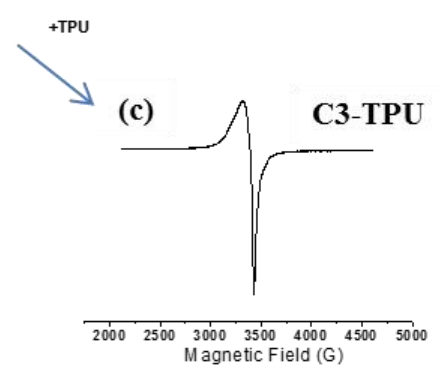

(f)
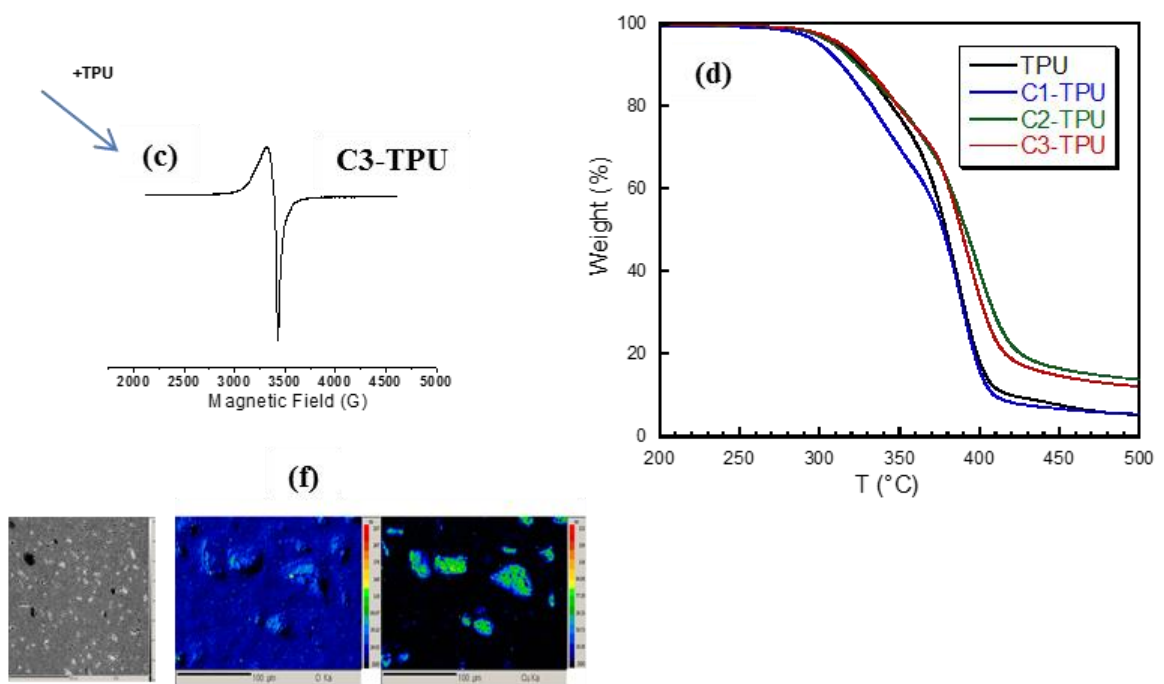

Figure 6. (a) Structure of C3. (b) CW-EPR spectrum of C3 at room temperature. (c) CW-EPR spectrum of C3-TPU at room temperature. (d) TGA profile (e) Crystalline C3 (f) EPMA on C3-TPU showing distribution.

\subsubsection{Thermal degradation and associated structural changes}

TGA profile of C3-TPU is much similar to C2-TPU (Figure 6d). C3-TPU starts to lose weight from $121^{\circ} \mathrm{C}$ (slow mass loss rate) until the onset of first step of decomposition $\left(268^{\circ} \mathrm{C}\right)$. The first step of decomposition shows loss of $25 \%$ weight until $359^{\circ} \mathrm{C}$. Volatile degradation products during this step were obtained from in situ operando technique of TGA-FTIR and was appropriately supported by py-GC/MS test. TGA-FTIR shows around $268^{\circ} \mathrm{C}$, the evolution of hydrocarbon $\left(2998,2874 \mathrm{~cm}^{-1}\right)$, small amount of $\mathrm{CO}_{2}$ (medium intensity of signals) (2371, 2308, 670 $\left.\mathrm{cm}^{-1}\right)$ species containing -C-OH and C-O-C group $\left(1079,912 \mathrm{~cm}^{-1}\right)$ and hydroxyl species (bands above $3594 \mathrm{~cm}^{-1}$ ). Based on the reported data and as seen in neat TPU this is assigned to butanediol which is also confirmed by py-GC/MS test. ${ }^{22,25}$ A carbonyl species $\left(1718 \mathrm{~cm}^{-1}\right)$ is seen around $310^{\circ} \mathrm{C}$ which could be a fraction containing urethane or ester. Residues were collected at the end of each TGA steps $\left(312^{\circ} \mathrm{C}, 359^{\circ} \mathrm{C}, 396^{\circ} \mathrm{C}\right)$ and were analysed by FTIR (Figure 7). 
FTIR of C3-TPU-359 (Figure 7) which is a stage after initial minor weight loss step shows that the band of urethane $\left(1702 \mathrm{~cm}^{-1}\right)$ has disappeared as seen in C2-TPU, NH stretch also decreased in intensity $\left(3349 \mathrm{~cm}^{-1}\right)$. It was already seen in case of L2-TPU that it is carbonyl stretching $\left(1704 \mathrm{~cm}^{-1}\right)$ of urethane group that undergoes reduction in intensity confirming our earlier observation that hard segment (HS) of TPU is the preferred choice of cleavage. ${ }^{22}$ Multiple bands around $1620 \mathrm{~cm}^{-1}$ due to $\mathrm{C} 3$ which is clearly visible in the spectrum of C3-TPU are now nearly disappeared and also the other prominent bands of C3. This means that C3 in TPU has further undergone severe structural changes by this stage.

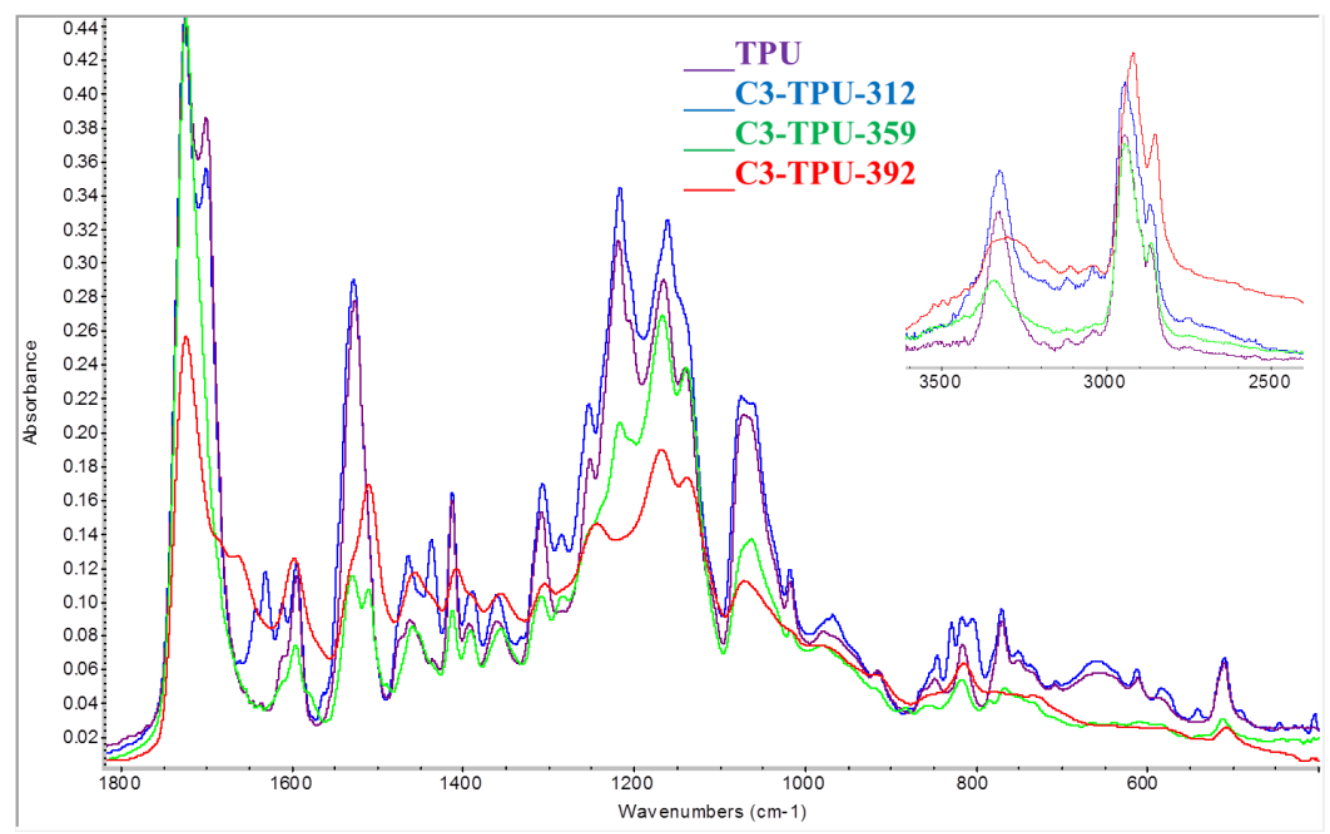

Figure 7. Structural changes followed by FTIR in the decomposition of C3-TPU.

Second step in TGA is slightly less gradual than C2-TPU and ended by $420^{\circ} \mathrm{C}$. The mass loss of volatiles was analysed by TGA coupled FTIR. At the beginning of this second step, hydrocarbon and $\mathrm{CO}_{2}$ are produced in large quantity along with carbonyl species and diols. There is an additional carbonyl band $\left(1770 \mathrm{~cm}^{-1}\right)$ which is due to cyclopentanone which is a cyclized product formed during the decomposition of TPU. This evolution is supported by pyGC/MS test. There is also contribution from linear ester fragments from soft segment (SS) of TPU which considerably increases as the $2^{\text {nd }}$ step reaches to its maximum weight loss. MDI (diphenyl isocyanate) although not evidenced in FTIR (overlapped by broad and strong $\mathrm{CO}_{2}$ band) was clearly identified in py-GC/MS of neat C3. From py-GC/MS chemical species like but-3-en-1-yl propionate (MW 128), but-3-en-1-yl pentanoate (MW 156), 4-hydroxybutyl pentanoate (MW 174), adipic acid 4-butenyl ester (MW 200), 4-hydroxy butyl adipic acid 
monoester (MW 218), dibutyl adipate (MW 254) are identified. There was no significant difference of their production in all formulations. It is highly likely that some of these species containing potential donor atoms may bind to copper ions and remains in the condensed phase. Residue collected around $400^{\circ} \mathrm{C}$ is studied by FTIR. Interestingly band at $1727 \mathrm{~cm}^{-1}$ is retained and is assigned to segmented polyol from TPU. This is expected to be involved in char formation. There are reports of involvement of hydrocarbon fragments in the formation of char due to radical formation. ${ }^{24}$ There are several additional bands around $1511 \mathrm{~cm}^{-1}$, and between $1600-1685 \mathrm{~cm}^{-1}$ which is the region characteristic of aromatic species. As the aromatic contributor MDI (from TPU) decompose completely by this was evidenced by py-GC/MS, the observed aromatic species are assumed to originate from C3. It can be recalled that the Salen precursor of C3 is capable of forming a phenolic resin type char upon thermal treatment. ${ }^{23}$ Independent investigations of $\mathrm{C} 3$ upon heating has shown interesting results. Microscopic analysis shows that sickle shaped microcrystals of C3 upon thermal treatment aggregate (Figure 8b), fuse and undergo particle level intumescence (each particle swells). We preassume that this process is also happening in the C3-TPU degradation but the process is complicated because of the presence of copper ions probably in different oxidation state and also because of the TPU matrix. There is also evidence (from py-GC/MS) of the presence of species like 4-phenoxyphenol in the volatiles which is an intermediate or a degradation product of poly-condensation of phenolic type resin which is also seen in hydroxyl Salen-TPU degradation. ${ }^{23,} 34$ Thus, char formation has contribution from structural transformation of C3 and stable fragments from unzipped TPU matrix mediated by C3.
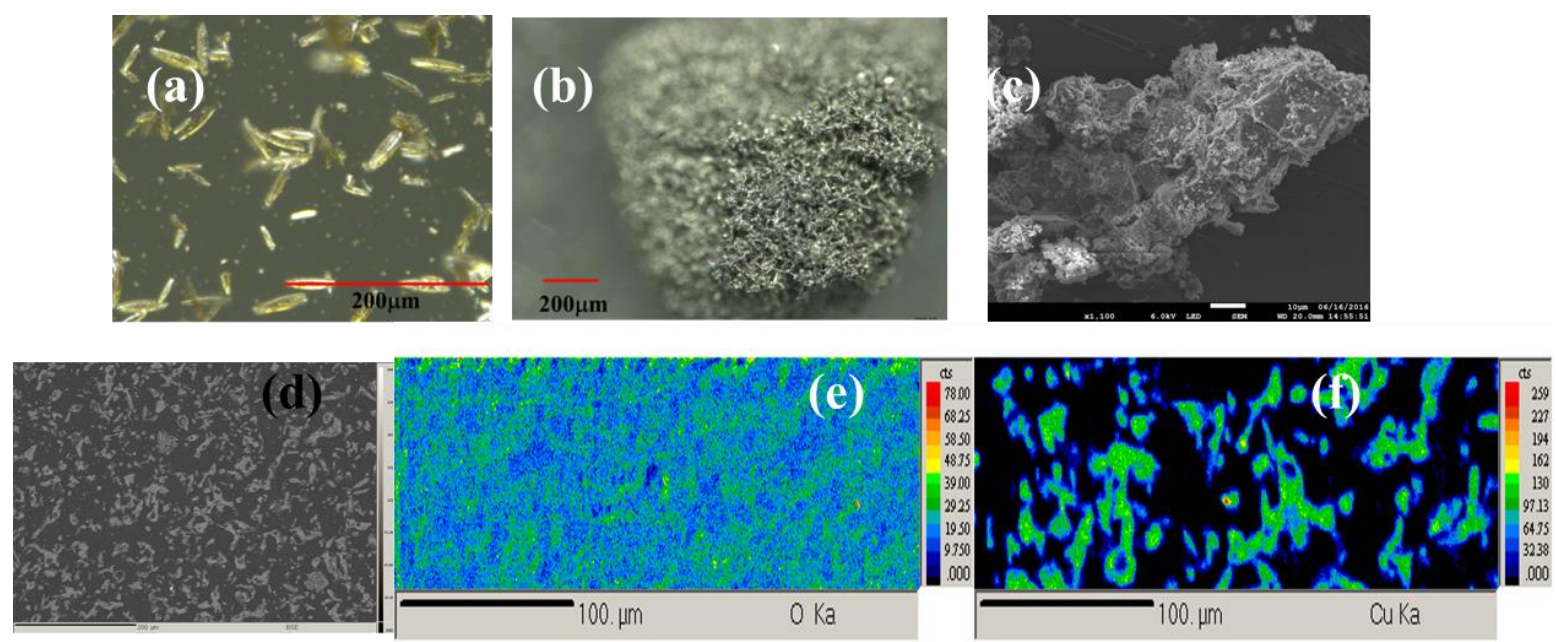

Figure 8. (a-c) Texture changes associated with $\mathrm{C} 3$ decomposition. (d-f) elemental mapping of the residue in $\mathrm{C} 3$ decomposition. 


\subsubsection{Fire behaviour investigation using EPR}

\subsubsection{Degradation study of C3-TPU under MLC experiment by CW EPR}

In order to explain the structural changes of the complexes embedded in TPU and the radical formation, CW-EPR was carried out on C3-TPU and TPU samples. Figure 9 displays the CWEPR spectra of powder collected at different MLC states i.e. onset, peak and end (residue) for C3-TPU and for neat TPU residue alone.
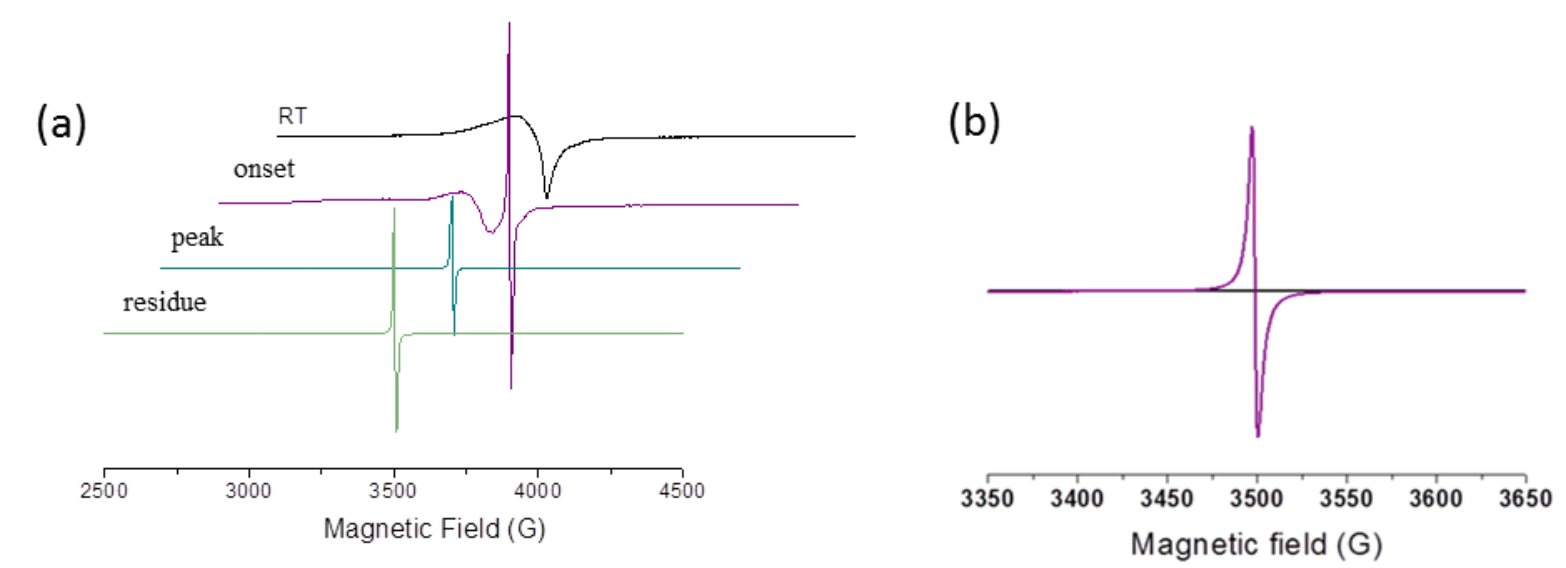

Figure 9. (a) CW-EPR spectra on C3-TPU degradation steps (sample collected at onset, peak and residues from MLC experiment). (b) CW-EPR spectrum of neat TPU (black line) and on residue (violet line).

As previously discussed, at room temperature C3-TPU spectrum shows a typical $\mathrm{Cu}$ (II) state signal. The onset spectrum permits to obtain the values of the two axial components of $\mathrm{g}$ factor $(\mathrm{g} \perp=2.06, \mathrm{~g} \|=2.19)$ together with the hyperfine constant $\mathrm{A} \|=204 \mathrm{G}$. As reported by Peisach and Blumberg ${ }^{42}$ the coordination of copper (II) is related to $\mathrm{g} \|$ and $\mathrm{A} \|$ values. These values reveal a copper with two nitrogen and two oxygen atoms coordination. In further MLC degradation steps, the $\mathrm{Cu}(\mathrm{II})$ signal disappears with a simultaneous formation of a strong and fine signal at ' $\mathrm{g}$ ' value of 2.002, typical of organic radicals. Two hypotheses can explain the existence of radical species: the degradation of TPU matrix or the hydroquinone component of Salen framework which has been released from copper ions. In order to investigate the first suggestion, powders of neat TPU (without additives) were investigated by CW-EPR, before and after thermal treatment. EPR result presents in Figure $9 \mathrm{~b}$ confirm the production of radical (g value of 2.002) at $600^{\circ} \mathrm{C}$ with the same EPR parameters observed before for C3-TPU. This value is characteristic of carbon centred radical. Radical formation has been reported in the degradation study of TPU. ${ }^{37}$ 
At this stage, paramagnetic copper (II) ions are assumed to undergo a redox chemistry leading to change oxidation state of copper (0, I, III). Indeed, copper (I) and (III) are EPR silent species which explain the disappearance of copper signal in Figure 9a. This is consistent with the reported ${ }^{36}$ work that showed the ability of the hydroxy-Salens to form the oxidizing $\mathrm{Cu}$ (III) species with the production of oxygen-based free radicals. XRD analysis (Figure10) on the residue shows that indeed copper exists in its oxide form $\left(\mathrm{Cu}_{2} \mathrm{O}\right.$ and $\mathrm{CuO}$ peaks are found $)$ and weak signal of metallic copper is also detected. During this degradation step, Salen framework detaches from copper ion and undergoes polycondensation leading resin type material. Experiments on C2-TPU showed similar conclusions like C3-TPU with the formation of radical species and the disappearance of copper in oxidation state (+II) (Figure S8).

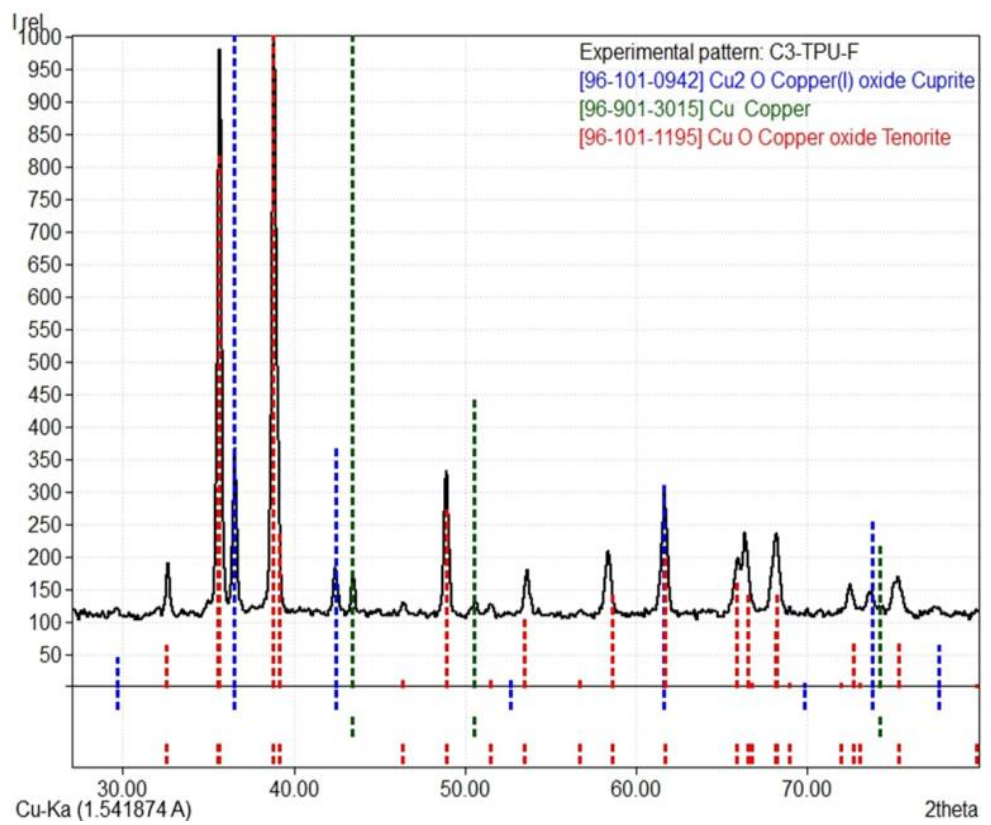

Figure 10. XRD of MLC C3-TPU residue.

\subsubsection{Investigation of the radicals origin: Characterization by in situ and ex situ CW EPR}

The CW-EPR spectrum of C3-TPU final residue permits to support that the oxidation state of $\mathrm{Cu}$ (II) changes to $\mathrm{Cu}_{2} \mathrm{O}, \mathrm{CuO}$ and a less extend to $\mathrm{Cu}^{\circ}$ accompanied with the organic radical formation.

The second proposition concerning the hydroquinone component of Salen framework was to study the CW-EPR of C3 complex without TPU. To explain the degradation product of this complex, two types of EPR experiments were compared: ex-situ EPR experiments which correspond to the analyze of the residue collected from TGA experiment and in-situ EPR 
experiments to follow directly radical species formation during the heating of the sample inside the EPR cavity. The EPR in situ approach permit to understand the origin of radical formation, their evolution and their nature as a function of the temperature and will be correlated with the ex-situ analyses. In-situ EPR characterization permit to obtain directly the relative quantity of species formed all along the experiment. Figure 11 presents EPR spectra evolution during thermal treatment. Changes in the EPR signals are similar on the both analysis. The initial EPR signal of copper (II) decreases whereas the organic radical EPR signal increases. The difference between signals shapes (ex-situ and in-situ) at room temperature is due to partial orientation of powder in the EPR tube and caused by the large grain size and the small amount of powder. At $330^{\circ} \mathrm{C}$, EPR spectrum (ex-situ mode) shows the presence of copper (II) with an axial symmetry $\left(\mathrm{g}_{/ /}=2.19\right.$ and $\left.\mathrm{g} \perp=2.04\right)$ and the hyperfine constant $\mathrm{A} / /=205 \mathrm{G}$. In the meantime, the organic radical with a fine and strong EPR signal $(\mathrm{g}=2.004)$ appears from $220{ }^{\circ} \mathrm{C}$ to $330^{\circ} \mathrm{C}$ and disappears at $600^{\circ} \mathrm{C}$. A radical recombination is suspected at higher temperature. These experiments confirm an intermediate copper complex with two nitrogen and two oxygen atoms coordination and the ability of copper complexes (without TPU) to produce radicals (probably oxygen centered) during thermal treatment. The degradation of $\mathrm{C} 3$ alone during heating forms radical species that are not able to maintain whereas radicals produced during the heating degradation of C3-TPU are more durable (more stable). It is noteworthy that Ex-situ and insitu results give similar conclusions.

These results suggest that the degradation of TPU at higher temperature contribute to create stable radical species (carbon centered radicals) quite different from radicals from copper complex (probably oxygen centered radicals).
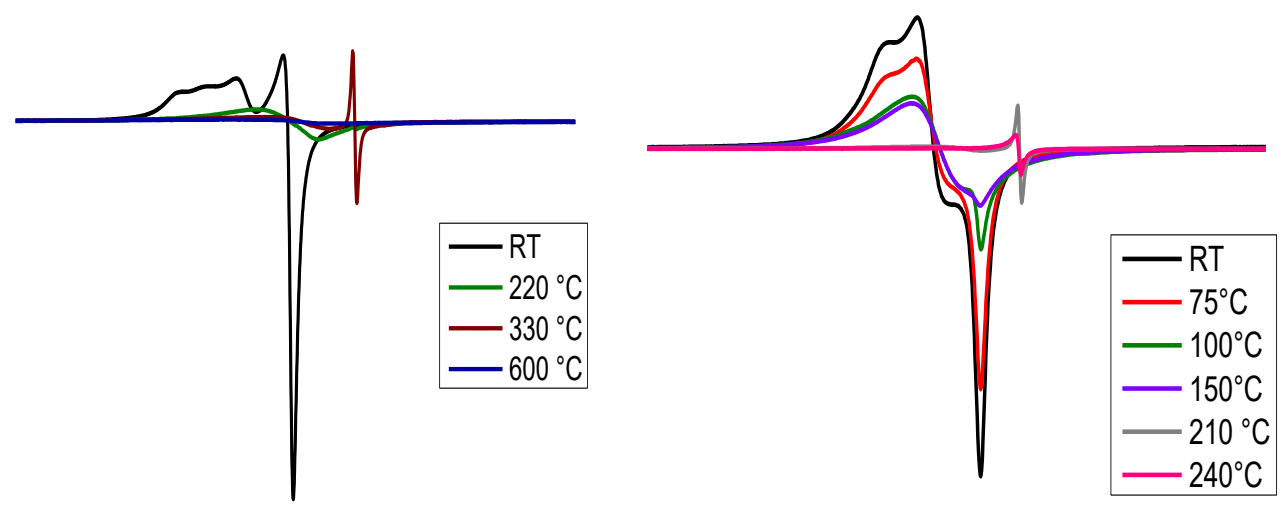
. ( (a) 
Figure11. CW-EPR spectra: comparison between ex-situ (left) and in-situ (right) thermal treatment of the neat $\mathrm{C} 3$ sample.

\subsubsection{Characterization of surrounding of the radicals by pulsed EPR}

To go further in understanding of C3-TPU behaviour, additional experiments were performed by using pulsed EPR spectroscopy on collected MLC samples (onset, peak and residue). 2pulses echo field sweep allows an orientation selection of the nuclear environments as observed in Figure 12. Two paramagnetic species are present: $\mathrm{Cu}$ (II) is observed for C3-TPU-onset and C3-TPU-peak while radicals are detected in all samples. Two types of radical species are detected in the residues: the first one at 3458G (C3-TPU-onset, $\mathrm{g}=2.0042$ ) and the second one at 3468G (C3-TPU-peak, g=2.0038) while both species are identified for C3-TPU-residue (radical at $3458 \mathrm{G}$ is predominant). As already seen by CW-EPR, C3-TPU-residue possesses a spectral fingerprint characteristic of organic radicals. Copper (II) is not observed which confirms a change of the oxidation state during the heat treatment. PEANUT experiment on C3-TPU-residue - wherein both radicals are detected - helps to reveal electronic structures of these radicals that give a direct access to spin state. The nutation spectrum is dominated by two intense peaks at $\omega_{\mathrm{TN}}{ }^{(\mathrm{A})} / 2 \pi=7.2 \mathrm{MHz}$ and $\omega_{\mathrm{TN}}{ }^{(\mathrm{B})} / 2 \pi=9.9 \mathrm{MHz}$ (Fig. 13).

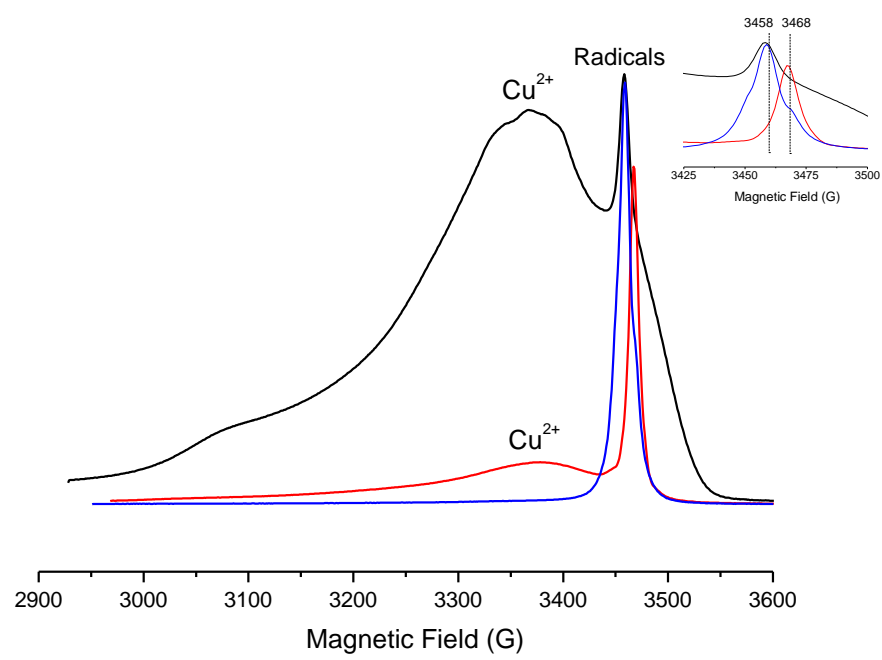

Figure 12. 2-pulses echo field sweep recorded at $5 \mathrm{~K}$ on the C3-TPU-onset (black line), C3TPU-peak (red line) and C3-TPU-residue (blue line) samples. 


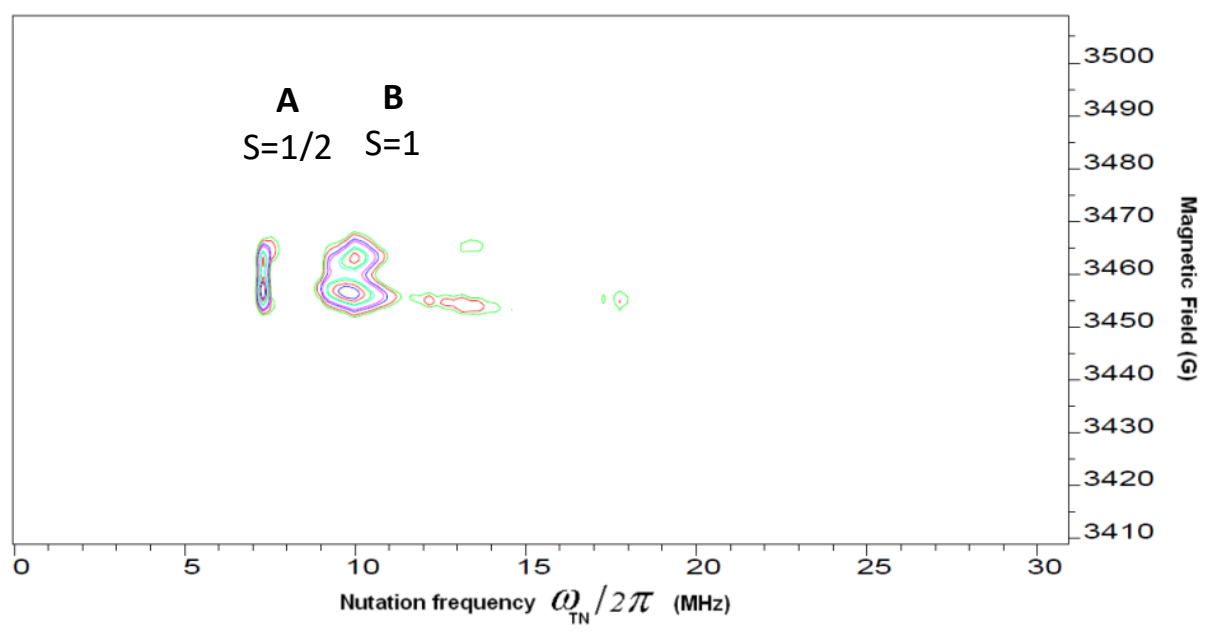

Figure 13: Transient nutation (PEANUT) experiment recorded on the C3-TPU-residue sample at $5 \mathrm{~K}$.

We expect $\omega_{\mathrm{TN}}=\mathrm{g} \beta \mathrm{B}_{1} / \mathrm{h}$ for radicals with $\mathrm{S}=1 / 2$ (single electron) and $\omega_{\mathrm{TN}}=\sqrt{2} \mathrm{~g} \beta \mathrm{B}_{1} / \mathrm{h}$ for biradicals with $S=1$ (two unpaired electrons). For the same type of radical (with the same gfactor) and the same incident microwave field $B_{1}$, the nutation frequency of a biradical $(S=1)$ is $\sqrt{2}$ times larger than for a single radical $(S=1 / 2)$. Nutation frequencies of $(A)$ and $(B)$ shown on Fig. 13 are related by $\omega_{\mathrm{TN}}{ }^{(\mathrm{B})} / \omega_{\mathrm{TN}}{ }^{(\mathrm{A})}=9.9 / 7.2=1.375 \cong \sqrt{2}$, which corresponds to $\mathrm{S}=1$ and $\mathrm{S}=1 / 2$ for (B) and (A), respectively. Also, it may be concluded that the existence of two nutation peaks with frequencies in a $\sqrt{2}$ ratio is a strong argument for the attribution of spins $S$ $=1 / 2$ and 1 to $(\mathrm{A})$ and $(\mathrm{B})$ species, respectively. This technique allowed demonstrating the existence of two different organic radicals in two spin state: one with single electron and another one with two unpaired electrons which correspond to biradical (two different organic radicals with $\Delta \mathrm{g}=0.0004)$. By combining the 2-pulses echo field sweep with PEANUT experiments, the results seem to show the presence of two radicals which are formed during the thermal treatment of C3-TPU. The first one is probably a carbon centered radical $(S=1 / 2)$ that is coming from the degradation of TPU which is more stable (mostly present in onset and residue samples) while the second one, probably an oxygen centered radical (biradical $S=1$ ) is from the degradation of complex alone (mostly present on peak sample-intermediate temperature).

Further it is useful to investigate how local nuclear environments of copper and radicals undergo changes at different stages of degradation. Thus, two-dimensional HYSCORE experiments are carried out. Spectra characteristic of the evolution of local surrounding of copper and organic radicals in all samples are presented in Fig. 14 and 15, respectively. 
The evolution of local chemical surrounding of $\mathrm{Cu}$ (II) in different samples collected from MLC experiment is shown in Fig.14. Whatever the sample, a strong coupling with ${ }^{14} \mathrm{~N}$ are observed in $(-,+)$ quadrant with coupling constant A of $6.6 \mathrm{MHz}$. This means that the ${ }^{14} \mathrm{~N}$ nuclei are very close to the unpaired electron of copper. In the $(+,+)$ quadrant a pair of cross peaks centered at ${ }^{14} \mathrm{~N},{ }^{13} \mathrm{C},{ }^{1} \mathrm{H}$ and ${ }^{63} \mathrm{Cu}$ nuclear Larmor frequencies are detected. All these nuclei are weakly coupled with the unpaired electron of copper (onset and peak samples). A drastic change in chemical environment with a strong contribution of nitrogen atoms at higher temperature was observed. Indeed, the ratio $\mathrm{C} / \mathrm{N}$ is very different for both samples: $\mathrm{C} 3-\mathrm{TPU}-$ onset and C3-TPU-peak. C3-TPU-onset presents two types of ${ }^{14} \mathrm{~N}$ nuclei characterized by coupling constants A of 6.6 (strong coupling) and $1.4 \mathrm{MHz}$ (weak coupling) while C3-TPUpeak possesses coupling constants A of 6.6 (strong coupling) and $5 \mathrm{MHz}$ (weak coupling) with the presence of $\mathrm{NH}$ group. The flat ridges of protons observed arises mainly from Fermi contact term corresponding to aliphatic protons. $\mathrm{Cu}$ (II) is coupled with 3 types of protons atoms characterized by couplings constant $\mathrm{A}$ of 3,7 and $20 \mathrm{MHz}$ corresponding to different hydrogens. It seems also that $\mathrm{Cu}$ (II) is coupled with diamagnetic copper atom which proves the rapid change of the oxidation state of a part of copper during the degradation of onset sample. For this sample, it is probable that a part of copper is oxidized into $\mathrm{Cu}$ (III) which is in proximity of $\mathrm{Cu}(\mathrm{II})$.

Figure 15 presents the evolution of local chemical environment of organic radicals. The carbon contribution is very significant in the chemical surrounding of radicals (coupling constants of $1 \mathrm{MHz}$ for $\mathrm{C} 3-\mathrm{TPU}-$ onset and $5 \mathrm{MHz}$ for C3-TPU-peak and residue) which means that the local microenvironment of radical species is carbonaceous. Despite the small natural abundance of ${ }^{13} \mathrm{C}(1.11 \%)$, an intense signal of carbon is observed in fig. 14 . This is due to the large number of carbon atoms located at short distances from the radical species and so, increases the probability for the unpaired electron to interact with a ${ }^{13} \mathrm{C}$ nucleus. Consequently, the probability of detecting the ${ }^{13} \mathrm{C}$ signal becomes high as the number of equivalent carbons increases. It seems that the organic radicals are localized on large molecule as char. C3-TPUonset and C3-TPU-peak are composed of two types of nitrogen atoms ( $\mathrm{A}=6.6$ and $1.4 \mathrm{MHz})$ while C3-TPU-residue exhibits a third type of nitrogen atom characteristic of NH group. Different types of protons are also observed with similar coupling constants $(A=3,7 \mathrm{MHz}$ and $20 \mathrm{MHz}$ ) but with an increase of dipolar part which corresponds to aromatic protons. Indeed, the thermal treatment leads to an aromatization of the carbon chains. 
Thus, it was observed a drastic change in chemical environment with a strong contribution of nitrogen atoms in sample collected at higher degradation stage from MLC which means that the residues contain nitrogen fragments of TPU or Salen framework bearing nitrogen atoms. In our earlier work ${ }^{23}$ we have seen that nitrogen was found to be present in the residue of Salen degraded product and we proposed that benzoxazine type resin formation from Salen molecules. Thus, the char are nitrogen rich residues.

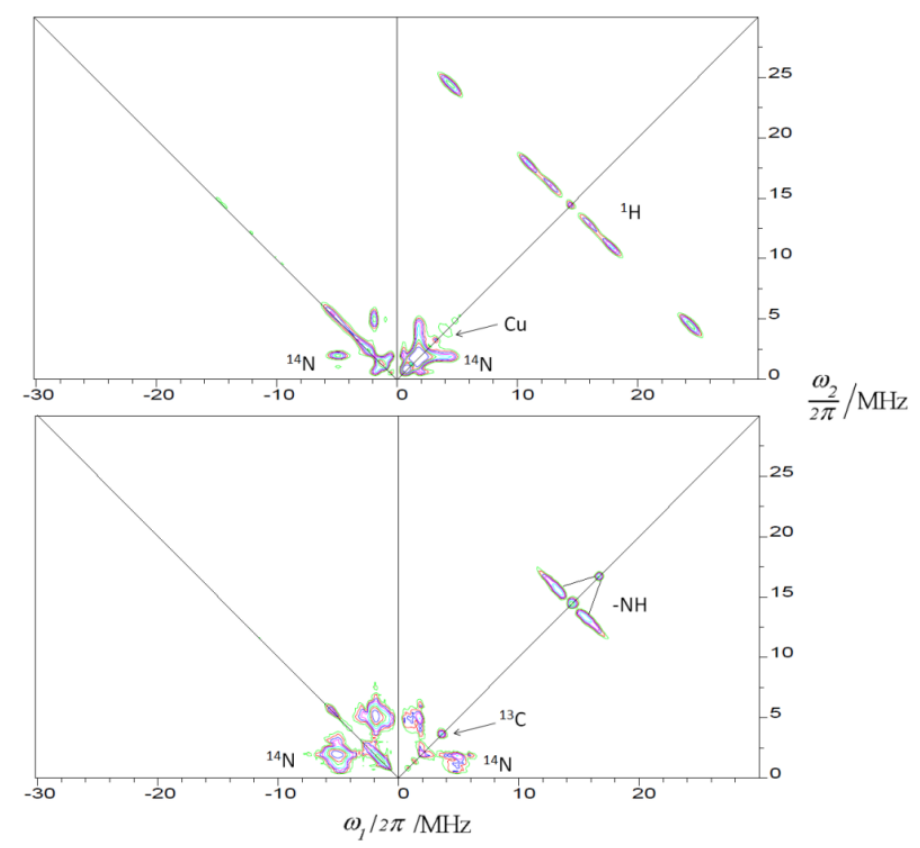

Figure 14. Evolution of the local chemical surrounding of $\mathrm{Cu}$ (II) by 2D-HYSCORE recorded on the C3-TPU-onset (top) and C3-TPU-peak (bottom) at $5 \mathrm{~K}$ and $3367 \mathrm{G}$. 


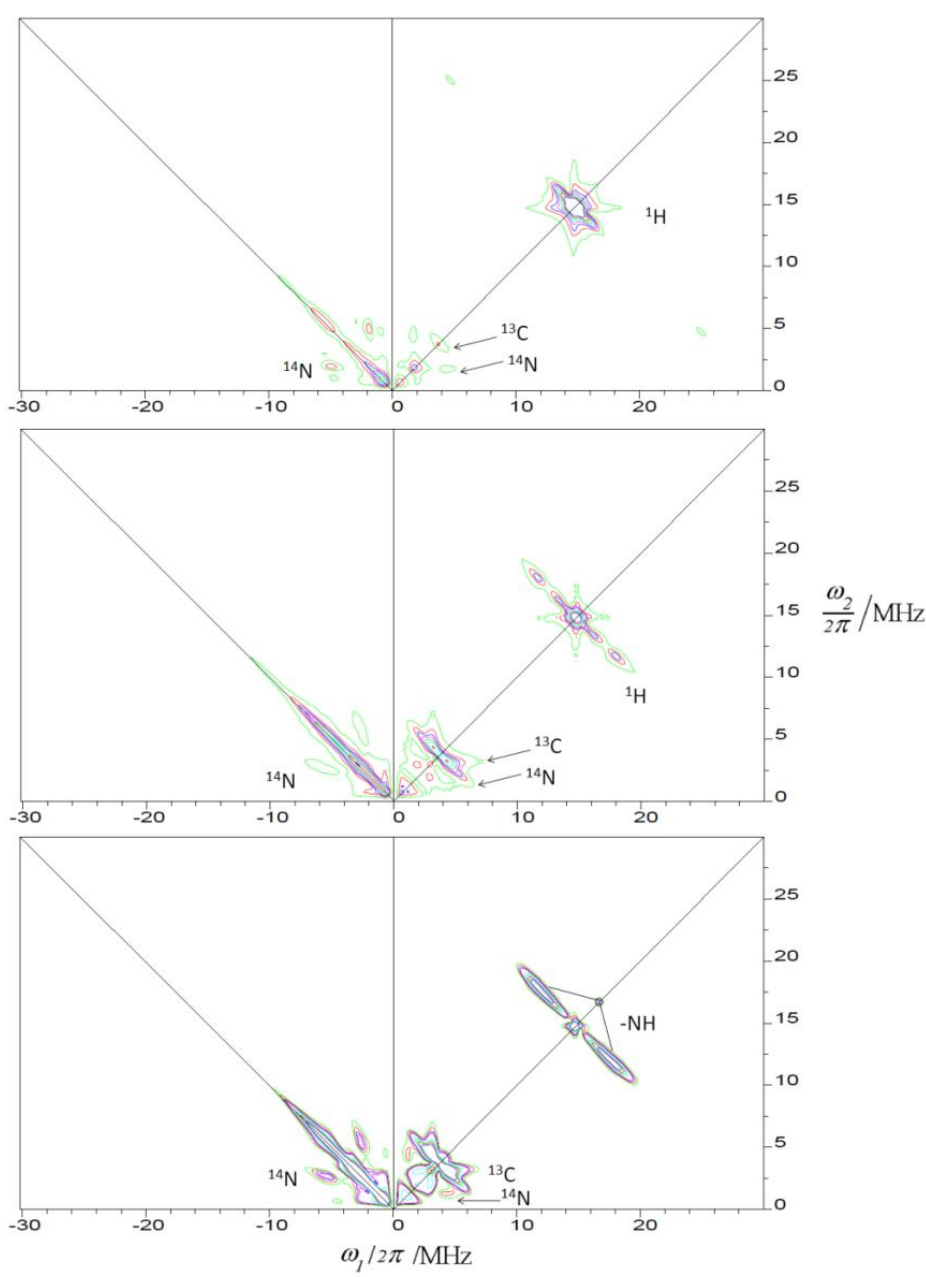

Figure 15. Evolution of the local chemical surrounding of organic radicals by 2D-HYSCORE recorded on the C3-TPU-onset (top), C3-TPU-peak (middle) and C3-TPU-residue (bottom) at $5 \mathrm{~K}$ and 3458 or $3468 \mathrm{G}$.

\subsubsection{Role of copper ions in the char}

Following section is dedicated to additional role of copper ions in the char. From the ongoing section, we also understood that copper oxides reinforce char. As copper oxide presence is prominent in the char and considering the reported ${ }^{10,11,13,14,41}$ catalytic role of oxides of copper we have studied the carbon monoxide production profile for TPU and TPU formulation. Results are obtained from MLC-FTIR experiment and figure S11 shows CO production profile for neat TPU, salen based TPU formulation (L2-TPU) and C2-TPU. It shows that TPU's CO evolution is shared over 3 regions. The middle being the highest ( $600 \mathrm{Vppm})$ and the last one is very broad ( $350 \mathrm{Vppm})$ and extends to the end. The curve is similar to TPU at the beginning in L2-TPU but drastically changes at later stages with significant increase in CO production. However, in C2-TPU the profile is very different (Figure S11). There is only one major peak at the beginning, like for TPU and L2-TPU, continuously decreasing as the decomposition 
progresses. The decreasing is assumed to be due to the catalytic activity of cuprous oxide (different copper species are identified in XRD) in the conversion of carbon monoxide.

\section{Mode of action:}

Based on the evidences obtained so far, the intumescence formation with C2-TPU or C3-TPU is found to be a combined contribution of copper complexes and TPU fragments that have cross-linking tendencies (Scheme 1). In our earlier work we have shown that the ligand of copper complexes play important role in the fire protection mechanism. ${ }^{23}$ Advantage of copper complexes here is the better thermal stability over its metal free ligand (by $30-40^{\circ} \mathrm{C}$ ) and involvement of its redox chemistry which are discussed in the following section.

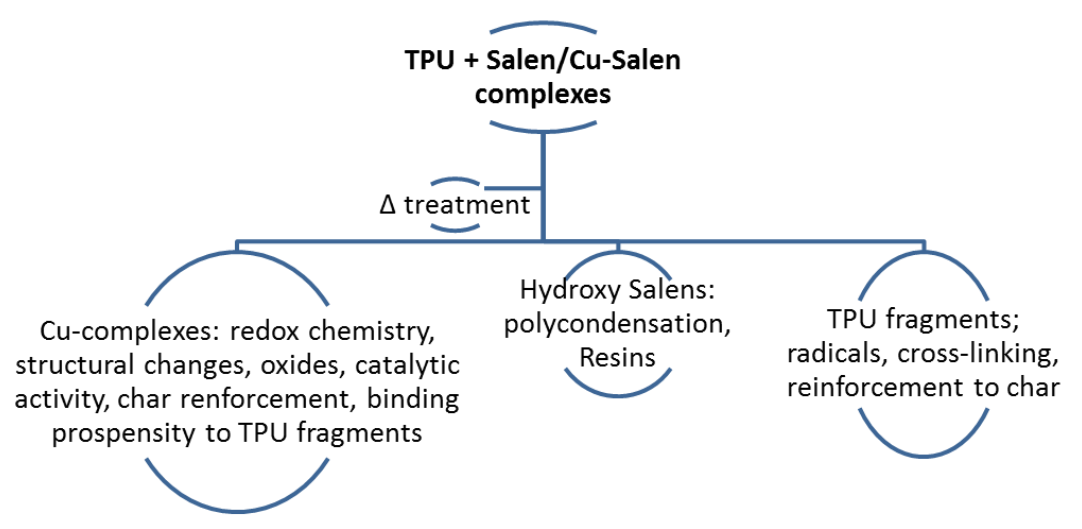

Scheme 1. An overview of participation of components of formulation in fire protection mechanism.

Hydrogen bonding connecting additives and TPU are loosen as the TPU matrix with additives is subjected to thermal treatment. Copper Salen starts to release coordinated water molecules. Further copper centres undergo redox reaction with subsequent change in oxidation states, coordination number and geometry before releasing into the matrix. This will be simultaneously accompanied by release of free hydroxyl Salen framework which is a potential molecule in the formation of heat resistant resins. Thereafter hydroxyl Salen cannot stay in its neat form but can undergo fragmentation as observed before to form reactive hydroxyl substituted phenols or $o$-quinone methide $(o$-QM) like intermediates in the resin formation pathway. ${ }^{23}$ The advantage of this fragmentation after demetalation is that it does not end up with decomposition of organic framework of ligand but instead steady organic transformation. 
In the present case, poly-condensation leading to phenolic resin type thermal protecting barrier is evidenced (Scheme 2). Thus, copper complexes can contribute as a precursor of phenolic resins. The whole process will influence the TPU unzipping pathway. Hydroxyl Salen during its polycondensation process also form some amount of benzoxazine or nitrogen containing resins. Collectively these resins are the source of char. C2 and C3 cannot direct same type of resin formation pathway in their TPU matrix as observed in case of metal free 4- and 5-hydroxy Salen which followed different routes in resin formation pathway. ${ }^{22,23}$

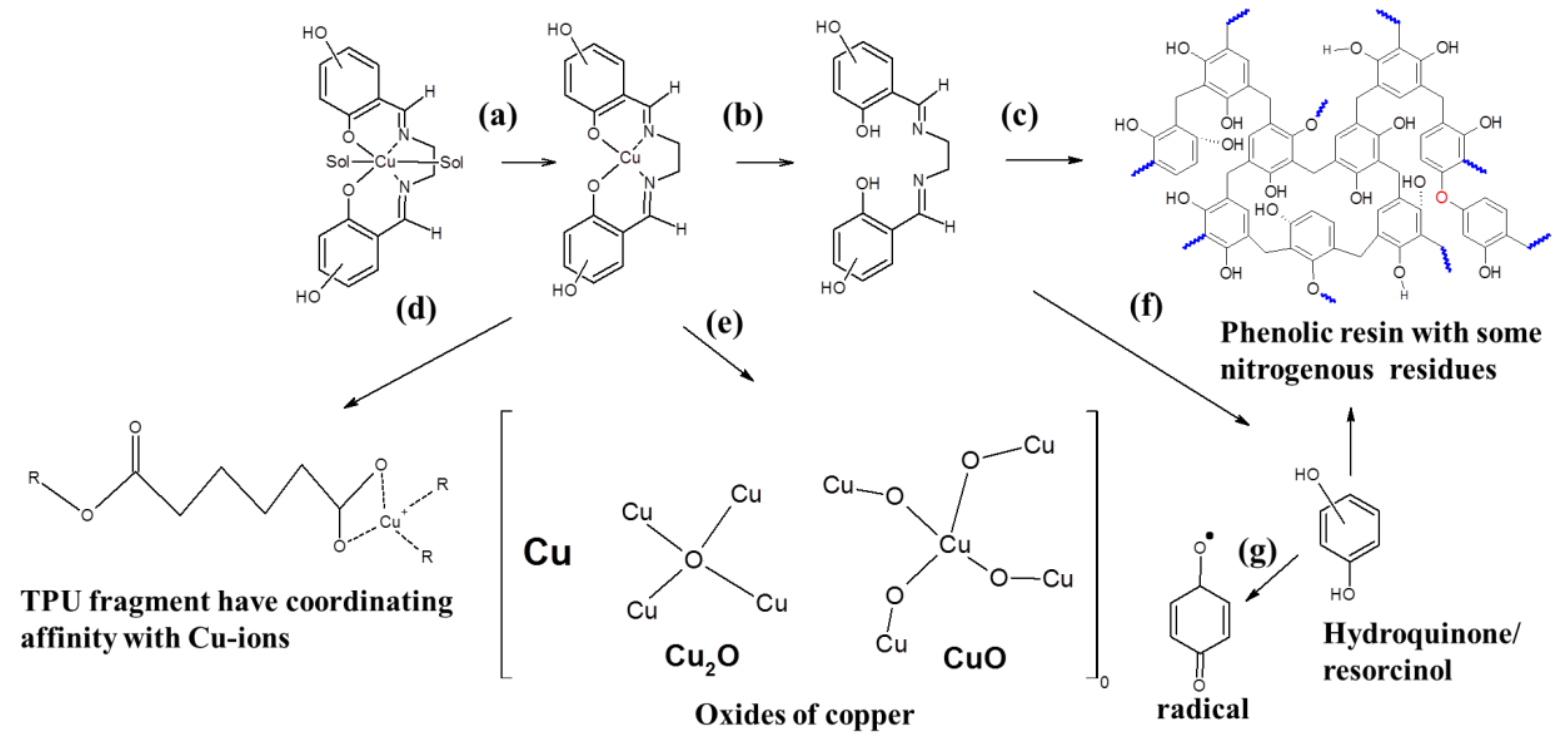

Scheme 2. Tentative degradation pathway of copper complexes in TPU.

Meanwhile, copper ions released into the matrix undergo several changes particularly oxide formation and integration into the char formation. Metal ions also can coordinate to fragmented section of TPU (with potential donor molecules) and keeps them in condensed phase (Scheme 2). Further advantage of formation of copper oxide lies in its catalytic activity. Cuprous oxide is known to exhibit synergistic effect on improving the flame retardancy of resins or polymers. ${ }^{41}$ Redox active species like $\mathrm{Cu}_{2} \mathrm{O}$ enters the redox cycle and catalyse the conversion of $\mathrm{CO}$ into $\mathrm{CO}_{2}$ and also acts as smoke suppressant which has been proved through both experimental and theoretical studies. ${ }^{41}$

TPU unzipping can follow more than one type of polymer unzipping. Primary target being the urethane group it is found that hard segment starts to break forming methylene diphenyl 
diisocyanate (MDI) and butane diol (BD). Although the primary target of degradation is urethane group, there is report that urethane segment is unaffected and methylene group of MDI oxidation forms benzophenone. ${ }^{37}$ Further soft segment of TPU having ester fragment undergoes thermo-oxidative degradation giving oligomers and some cyclized products depending upon the TPU unzipping process. ${ }^{37,38}$ MDI once released can act as cross-linker and thus retained in the condensed phase. TPU unzipping process under these circumstances may favour the production of larger TPU fragments and less combustible materials. These fragments having potential donor atoms encapsulate copper ions and contribute to the matrix of char.

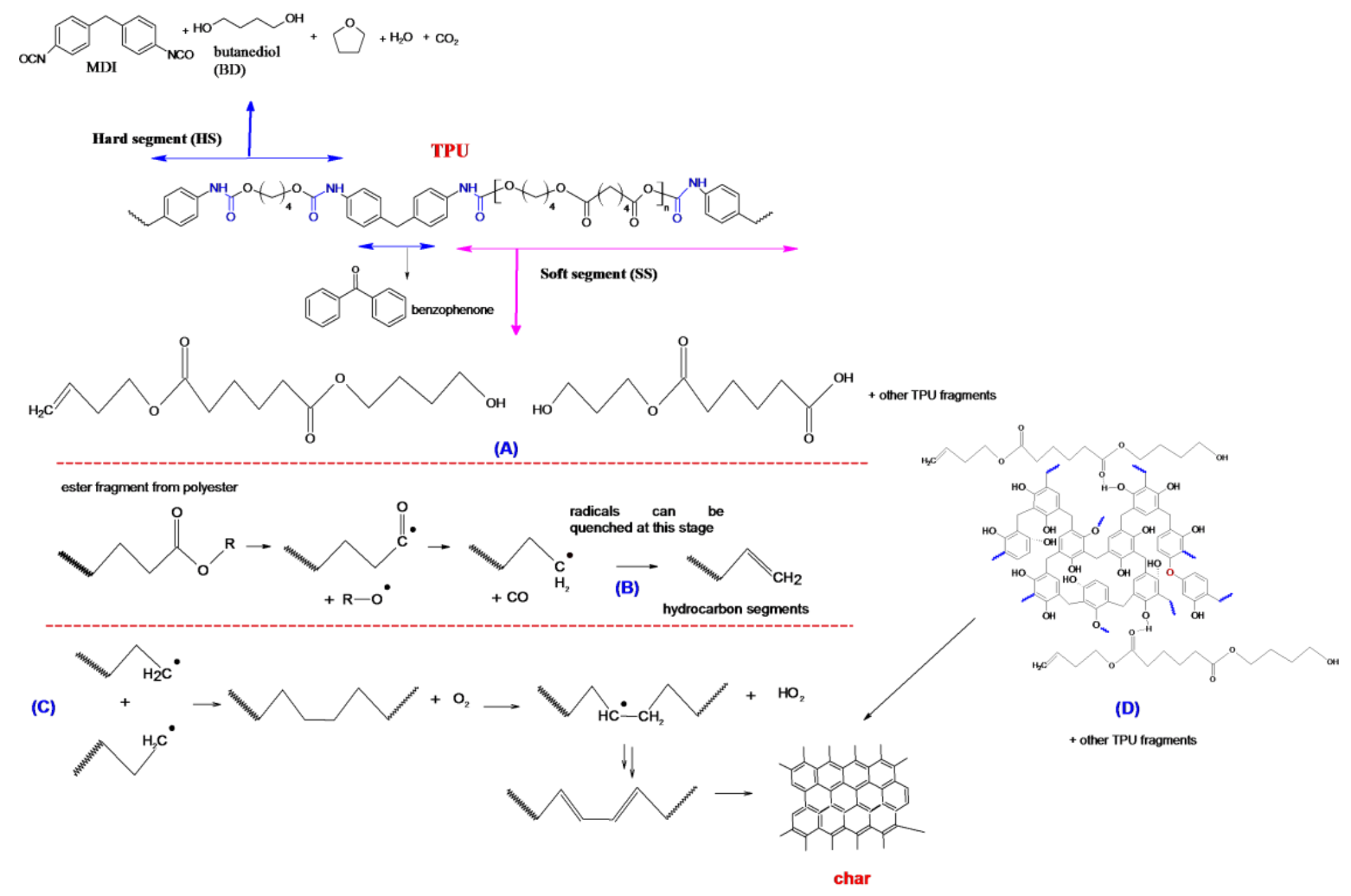

Scheme 3. Tentative and simplified degradation pathway in formulations.

Radical based polymerisation of hydrocarbon residues from TPU is known and is also expected to contribute to the char formation in present case. The free radical cross-linking of TPU ${ }^{39}$ fragments is considered to involve the generation of free radical positions in the polyurethane chains. Methylene sites are suggested for free-radical formation. Initially ester segment breaks between carbonyl-O bond and produce carbonyl radical and alkoxy radical evolving to methylene radical and the coupling of these radicals takes place (Scheme 3) to form $\mathrm{C}-\mathrm{C}$ covalent chemical cross-links. Propagation of radical formation can be quenched by $\mathrm{FR}^{24}$ or its fragments and thus formation of some smaller segment of hydrocarbons is possible which can 
lead to dripping. On the other hand, if free radical addition proceeds unopposed then the process of cross linking of segments proceed with the formation of char (passing through stages such as diene, polyene, polyaromatics and finally char) (scheme 3). These above two processes are respectively happening in C3-TPU and C2-TPU. We have seen from EPR studies that radical generation is possible both with hydroxyl Salen and also with TPU matrix. Additional EPR results described on radicals are helpful particularly in understanding spin states of radicals (by PEANUT experiment) and local nuclear environment changes (by 2D-HYSCORE experiment).

Although intumescence is evidenced during the fire test on C2-TPU but it is not strong enough to sustain for longer time. It is due to surface quality of char and overall physical strength of char particularly upper surface of char. It is observed that there are few red patches over the intumescence (Figure 16 c). Sample after LOI test also shows this tendency of formation of red patches. This area on char (e.g. char from MLC) cracks under high heat flux and are possibly responsible for the second pHRR (Figure 2a). Residues containing this red patches were analysed by XRD (Figure 10) which shows formation of $\mathrm{CuO}, \mathrm{Cu}_{2} \mathrm{O}$ and metallic copper. Copper oxide is known to integrate into the char and is assumed to strengthen the char. However precipitation of metallic copper $(\mathrm{Cu})$ fails to integrate into chars into chars forming porous regions created by $\mathrm{Cu}$ metal. This poor cohesion of intumescence leads to cracks and pores (Figure 16). Also such regions on char pass through a stage of smouldering effect that (prolonged localised heating) oxidises the char at localized points precipitating metallic copper. This weakens the char.
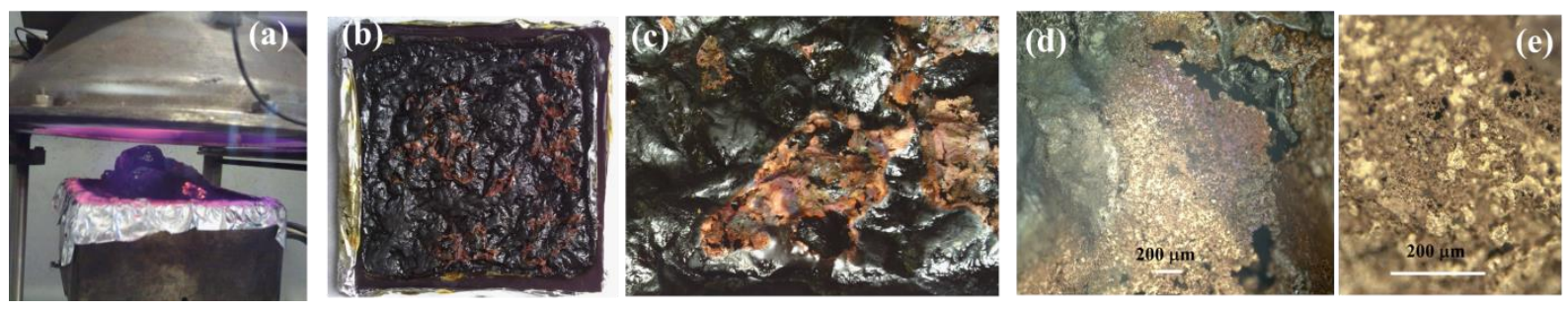

Figure 16. (a) Char formation as seen in MLC experiment in C2-TPU. (b) Sample collected at the onset of experiment (c) red patches on the char on the char collected at 'onset' $(d, e)$ Focussed images on red patches. 

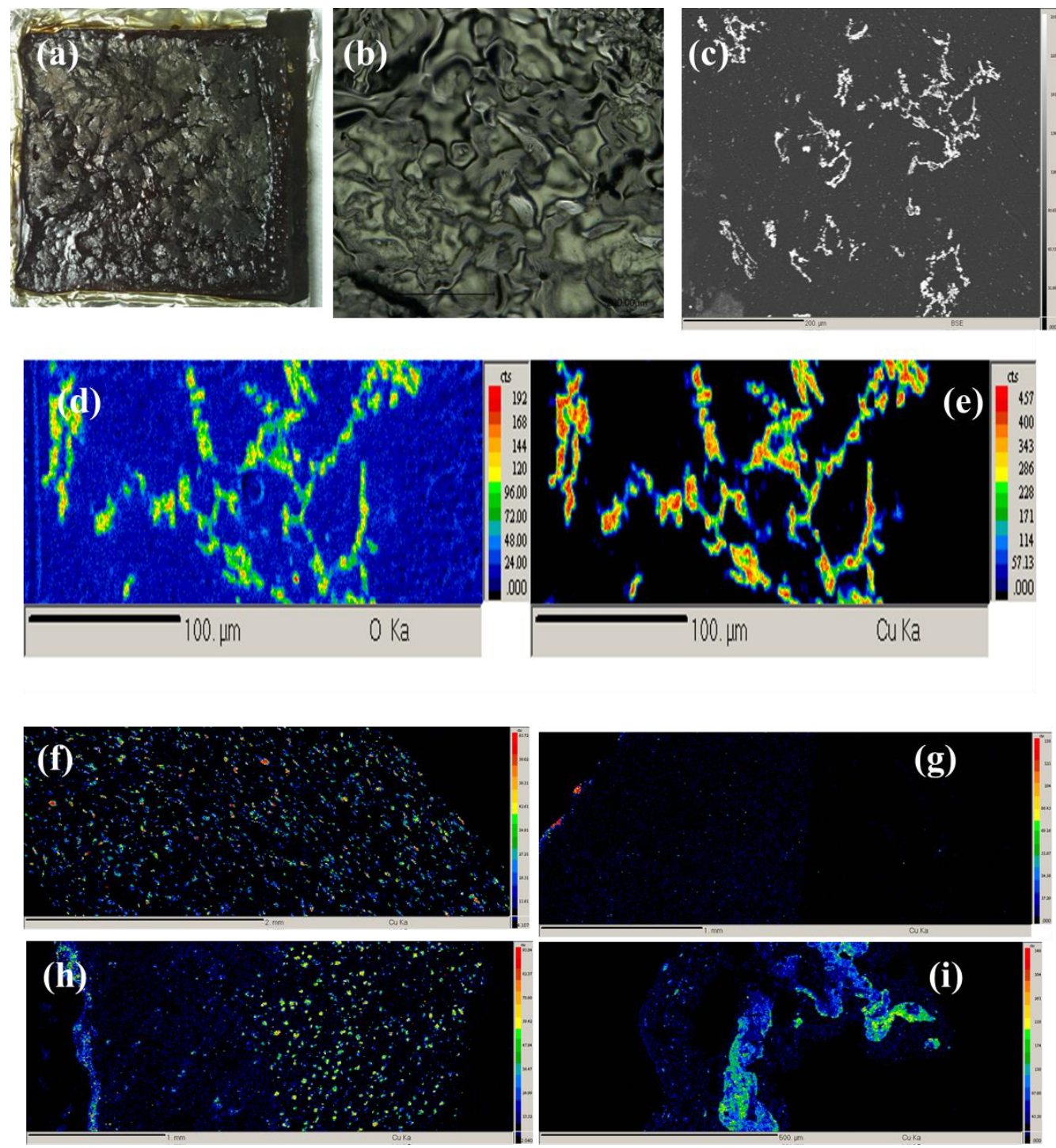

Figure 17. Textural changes in C3-TPU. (a) C3-TPU sample from cone calorimetry experiment stopped at peak of pHRR. (b) Focussed image (c) BSE image on residue from TGA $(\mathrm{d}, \mathrm{e})$ elemental mapping on residue (f-i) EPMA on residue showing localization of copper complexes in the sample. (f) Neat C3-TPU. (g) C3-TPU-onset. (h) C3-TPU-peak. (i) C3-TPUchar.

On the other hand the occasional red patches seen in C2-TPU over the intumescence which is due to precipitation of metallic copper are not seen in C3-TPU and their deleterious effect is minimized due to their submergence in highly viscous swelled /flexible char (Figure $16 \mathrm{a}, \mathrm{b}$ ). It should be reminded that L3 also mainly works by a kind of dripping (highly viscous residue) and follow different type of phenolic resin formation. ${ }^{24}$ This kind of flexible char under high heat flux does not cracks and possibly responsible for delayed TTI and pHRR reduction. Thus, C3-TPU works mainly by flexible char formation. Another interesting observation is the 
formation of copper depletion zone in the residues (residue from MLC experiment). It is due to migration (Figure 17f) of additives to the surface upon exposure to high temperature which then leaves behind resin forming hydroxyl Salen and concentrate at the surface by reinforcing char surface.

Although there is not significant contribution to gas phase action certain observations are worth noticing. We have seen from PCFC that both peaks of C2-TPU are reduced compared to neat TPU. This reduction is not seen in other complexes. Therefore, there is some contribution to the gas phase action of flame retardancy. This could be passive pathway of reduction in flammable material or active way of quenching of radicals and/or dilution of combustible material. If we compare weight loss in the first step of TGA (16\%), it is comparatively lower in C2-TPU meaning promotion of char formation. From Py-GC/MS results, it is interesting to note that cyclopentanone produced is greatly minimised indicates changes in the mode of polymer unzipping. Resorcinol which is a known radical scavenger is clearly detected in pyGC/MS of neat $\mathrm{C} 2$ although its detection in C2-TPU is difficult. This may also contribute to flame retardancy either in the gas phase or condensed phase by radical scavenging. ${ }^{40}$ Thus it seems that the reduction in gas phase is partially due to reduction of flammable material.

Thus far, we have seen that how copper complexes undergo structural changes upon thermal treatment maximising char formation, minimizing formation of flammable products, contributing in the oxide forms to the flame retardancy.

\section{Conclusion:}

Fire protection by Salen complexes described in this work underline the advantages of using metal complexes as fire retardants. Complexation not only increase the thermal stability compared to un-complexed Salen but also provide a platform for structural transformation forming resin like insulating materials. Metal ions released during heat treatment reinforce char and have some catalytic role in the smoke production. Another advantage of complexation is to avoid unnecessary coordination of metal ions (when used in uncomplexed form) with potential donor sites on polymer thus this lower the risk of altering the physical and chemical properties of the matrix. Salen in our case works without a synergist and mostly perform in the condensed phase although gas phase action could not be ruled out. However, additional synergist could even enhance the overall efficiency. Moreover, by the variation of the functional groups on the FR, the secondary interaction and molecular organization with the host matrix can be controlled and thus its functional properties can be influenced. Redox active 
metal ions (and also metal ions like lanthanides with higher coordination numbers) involving paramagnetism, although not as easy as diamagnetic metal ions to follow, may have curious but interesting properties during their change in oxidation states. We have seen in the present study how EPR techniques could be an important tool as complementary technique of solid state NMR in characterising the steps involved in elucidating the flame retardancy. Present study has demonstrated that formulations with paramagnetic metal ions and radical formation can be easily tracked by EPR. Further advanced EPR techniques like PEANUT, 2D HYSCORE can be explored to study spin states of radicals and local environment of radical respectively in the elucidation of mechanism of action of flame retardancy. Overall, the study has demonstrated that tailored classical metal complexes will have huge prospects in flame retardancy.

Acknowledgment: The authors are grateful to the French national EPR facilities network (IR CNRS 3443). We acknowledged IRCP laboratory which permitted us to perform High Temperature EPR studies.

\section{References:}

1. Morgan, A.B.; A Review Of Transition-Metal Based Flame Retardants: Transition Metal Oxides/Salts, And Complexes, Fire And Polymers V, Chapter 19, pp 312-328, ACS Symposium Series, Vol 1013.

2. Levchik, S.V.; Levchik, G.F.; Camino, G; Costa, L; Lesnikovich, A.I. Mechanism Of Action Of Phosphorus-Based Flame Retardants In Nylon 6. III. Ammonium Polyphosphate/Manganese Dioxide Fire Mater. 1996, 20,183-190.

3. Davies, P.J.; Horrocks, A.R.; Alderson, A. The Sensitization Of Thermal Decomposition Of Ammonium Polyphosphate By Selected Metal Ions And Their Potential For Improved Cotton Fabric Flame Retardancy. Polym. Degrad. Stab. 2005, 88, 114-122.

4. Wang, DY.; Liu, Y; Wang, YZ.; Artiles, CP.; Hull TR.; Price D. Fire Retardancy Of A Reactively Extruded Intumescent Flame Retardant Polyethylene System Enhanced By Metal Chelate. Polym. Degrad. Stab. 2007, 92, 1592-1598.

5. Wang, D.Y.; Liu, Y; Ge, X.G.; Wang, Y.Z.; Stec, A; Biswas, B; Hull; R.T.; Price, D. Effect Of Metal Chelates On The Ignition And Early Flaming Behaviour Of Intumescent Fire-Retarded Polyethylene Systems. Polym. Degrad. Stab. 2008, 93,1024-1030. 
6. Tian, C.M.; Qu, H.Q.; Wu, W.H.; Guo, H.Z.; Xu, J.Z. Metal Chelates As Synergistic Flame Retardants For Flexible PVC J. Vinyl Addit. Technol. 2005, 11, 70-75.

7. Nodera, A; Kanai, T. Thermal Decomposition Behavior And Flame Retardancy Of Polycarbonate Containing Organic Metal Salts: Effect Of Salt Composition J. Appl. Polym. Sci. 2004, 9, 2131-2139.

8. Wang, D.L.; Liu, Y.; Wang, D.Y.; Zhao, C.X.; Mou, Y.R.; Wang, Y.Z. A Novel Intumescent Flame-Retardant System Containing Metal Chelates For Polyvinyl Alcohol Polym. Degrad. Stab. 2007, 92, 1555-1564.

9. Wu, N.; Yang, R. Effects Of Metal Oxides On Intumescent Flame-Retardant Polypropylene, Polym. Adv. Tech. 2011, 22, 495-501.

10. Zhou, Y.; Liu, X.; Wang, F.; Hao, J.-W.; Du, J.-X. Effect Of Metal Oxides On Fire Resistance And Char Formation Of Intumescent Flame Retardant Coating J. Inorg. Mater. 2014, 29, 972-978.

11. Wang, L., Yang, W.; Wang, B.; Wu, Y.; Hu, Y.; Song L.; Yuen; R. K. K. The Impact Of Metal Oxides On The Combustion Behavior Of Ethylene-Vinyl Acetate Coploymers Containing An Intumenscent Flame Retardant, Ind. Eng. Chem. Res., 2012, 51, 78847890 .

12. Wu, J.; Hu, Y.; Song, L.; Kang, W. Synergistic Effect Of Lanthanum Oxide On Intumescent Flame-Retardant Polypropylene-Based Formulations; J. Fire Sci. 2008, 26, $399-414$.

13. Metal Catalysed Intumescence Of Polyhydroxyl Compounds, Phd Thesis, 2003, University Of Pretoria, By F.J.W.J. Labuschagne.

14. Lin, M.; Li, B.; Li, Q.; Li, S.; Zhang, S. Synergistic Effect Of Metal Oxides On The Flame Retardancy And Thermal Degradation Of Novel Intumescent Flame-Retardant Thermoplastic Polyurethanes, Applied Polymer Sci. 2011, 121, 1951-1960.

15. Fontaine, G.; Turf, T.; Bourbigot, S. Salen Copper Complexes: A Novel Flame Retardant For Thermoplastic Polyurethane, Fire And Polymers V, Chapter 20, Acs Symposium, 2009, 1013, 329.

16. Sheng, W. J.; Liu, Y.; Zhao, H.-B.; Liu, J.; Wang, D.-Y.; Song, Y.-P.; Wang, Y.-Z. Metal Compound-Enhanced Flame Retardancy Of Intumescent Epoxy Resins, Containing Ammonium Polyphosphate, Polym. Degrad. Stab. 2009, 94, 625-631.

17. Naik, A.D.; Fontaine, G.; Samyn, F.; Delva, X.; Bourgeois, Y.; Bourbigot, S. Melamine Integrated Metal Phosphates As Non-Halogenated Flame Retardants: Synergism With 
Aluminium Phosphinate For Flame Retardancy In Glass Fiber Reinforced Polyamide 66 Polym. Degrad. Stab. 2013, 98, 2653-2662.

18. Naik, A.D.; Fontaine, G.; Samyn, F.; Delva, X.; Louisy, J.; Bellayer, S.; Bourgeois, Y.; Bourbigot, S. Outlining The Mechanism Of Flame Retardancy In Polyamide 66 Blended With Melamine-Poly(Zinc Phosphate) Fire Safety J. 2014, 70, 46-60.

19. Gardelle, B.; Duquesne, S.; Vandereecken, P.; Bellayer, S.; Bourbigot, S. Resistance To Fire Of Intumescent Silicone Based Coating: The Role Of Organoclay Prog. Org. Coat., 2013, 76, 1633-1641.

20. Kilinc, M. Silicon Based Flame Retardants. In: Morgan A.B. And Wilkie C.A. (Eds) Non-Halogenated Flame Retardant Hand Book. Hoboken, NJ: John Wiley \& Sons, Inc., 2014.

21. Fontaine G.: Metal-Organic Frameworks : New Fire Retardant For Polymeric Materials, F.R.P.M. 2017, Manchester, Uk

22. Naik, A. D.; Fontaine, G.; Bellayer, S.; Bourbigot, S. Salen Based Schiff Bases To Flame Retard Thermoplastic Polyurethane Mimicking Operational Strategies Of Thermosetting Resin, RSC Adv. 2015, 5, 48224-48235.

23. Naik, A. D.; Fontaine, G.; Bellayer, S.; Bourbigot, S. Crossing The Traditional Boundaries: Salen-Based Schiff Bases For Thermal Protective Applications, ACS Appl. Mater. Interfaces 2015, 7, 21208-21217.

24. Chattopadhyay, D.K.; Webster, D.C. Thermal Stability And Flame Retardancy Of Polyurethanes Prog. Polym. Sci. 2009, 34, 1068-1133.

25. Tabuani, D.; Bellucci, F.; Terenzi, A.; Gamino, G. Flame Retarded Thermoplastic Polyurethane (TPU) For Cable Jacketing Application Polym. Degrad. Stab., 2012, 97, 2594.

26. HöFer, P.; Grupp, A.; Nebenfürh, H.; Mehring, M. Hyperfine Sublevel Correlation (Hyscore) Spectroscopy: A 2d ESR Investigation Of The Squaric Acid Radicalchem Phys. Lett. 1986, 132, 279-282.

27. Astashkin, A. V.; Schweiger A. Electron-Spin Transient Nutation: A New Approach To Simplify The Interpretation Of ESR Spectra. Chem. Phys. Lett. 1990, 174, 595-602.

28. Baker, E.N.; Hall, D.; Waters, T.N. The Color Isomerism And Structure Of Copper CoOrdination Compounds. Part X. The Crystal Structure Of Bis-Salicylaldiminatocopper (II) J. Chem. Soc., A, 1966, 680-684.

29. http://www2.basf.us/urethanechemicals/tpu/pdf/c85a.pdf 
30. Rosu, D.; Tudorachi, N.; Rosu, L. Investigations On The Thermal Stability Of A Mdi Based Polyurethane Elastomer Anal. J. Appl. Pyro. 2010, 89, 152.

31. Moo Espinosa, J.I.; Cauich-Rodríguez, J.V.; Ávila-Ortega, A.; Vázquez-Torres, H.; Marcos-Fernández, A.; San Román, J. Cervantes-Uc J.M. TGA/FTIR Studies Of Segmented Aliphatic Polyurethanes And Their Nanocomposites Prepared With Commercial Montmorillonites, Polym. Degrad. Stab. 2009, 94, 1666-1677.

32. Herrera, M.; Matuschek, G.; Kettrup, A. Thermal Degradation Of Thermoplastic Polyurethane Elastomers (TPU) Based On MDI Polym. Degrad. Stab. 2002, 78, 323-331.

33. Berta, M.; Lindsay, C.; Pans, G.; Camino, G. Effect Of Chemical Structure On Combustion And Thermal Behaviour Of Polyurethane Elastomer Layered Silicate Nanocomposites Polym. Degrad. Stab. 2006, 91, 1179-1191.

34. Hesse, W.; Lang, J. Phenolic Resins, Ullmann's Encyclopedia Of Industrial Chemistry, $2000,26,583$.

35. Schartel, B.; And Hull, T. R. Development Of Fire-Retarded Materials-Interpretation Of Cone Calorimeter Data. Fire Mater. 2007, 31, 327-354.

36. K.-H., Mcbride M.B. Electron Transfer Processes Between Hydroquinone And Iron Oxides Kung Clays Clay Miner. 1988, 36, 303-309.

37. Zaikov, G.E.; Lomakin, S.M. New Aspects Of Ecologically Friendly Polymer Flame Retardant Systems Polym. Degrad. Stab. 1996, 54, 223-233.

38. Servay, T.; Voelkel, R.; Schmiedberger, H.; Lehmann, S. Thermal Oxidation Of The Methylene Diphenylene Unit In MDI-TPU Polymer 2000, 41, 5247-56.

39. Handbook Of Elastomers, Second Edition, Bhowmick A.K.; Stephens H.; CRC Press, 2000, 265.

40. Thavasi, V.; Phillip, R. Bettens A.; Leong L. P. Temperature And Solvent Effects On Radical Scavenging Ability Of Phenols Phys. Chem. A 2009, 113, 3068-3077.

41. Chen, M-J.; Lin, Y-C.; Wang, X-N.; Zhong, L.; Li, Q-L; Liu, Z-G. Influence Of Cuprous Oxide On Enhancing The Flame Retardancy And Smoke Suppression Of Epoxy Resins Containing Microencapsulated Ammonium Polyphosphate, Ind. Eng. Chem. Res. 2015, $54,12705-12713$.

42. Peisach, J.; Blumberg, W.E. Structural Implications Derived From The Analysis Of Electron Paramagnetic Resonance Spectra Of Natural And Artificial Copper Proteins, Arch. Biochem. Biophys.1974, 165, 691-708. 


\section{Graphical Abstract}

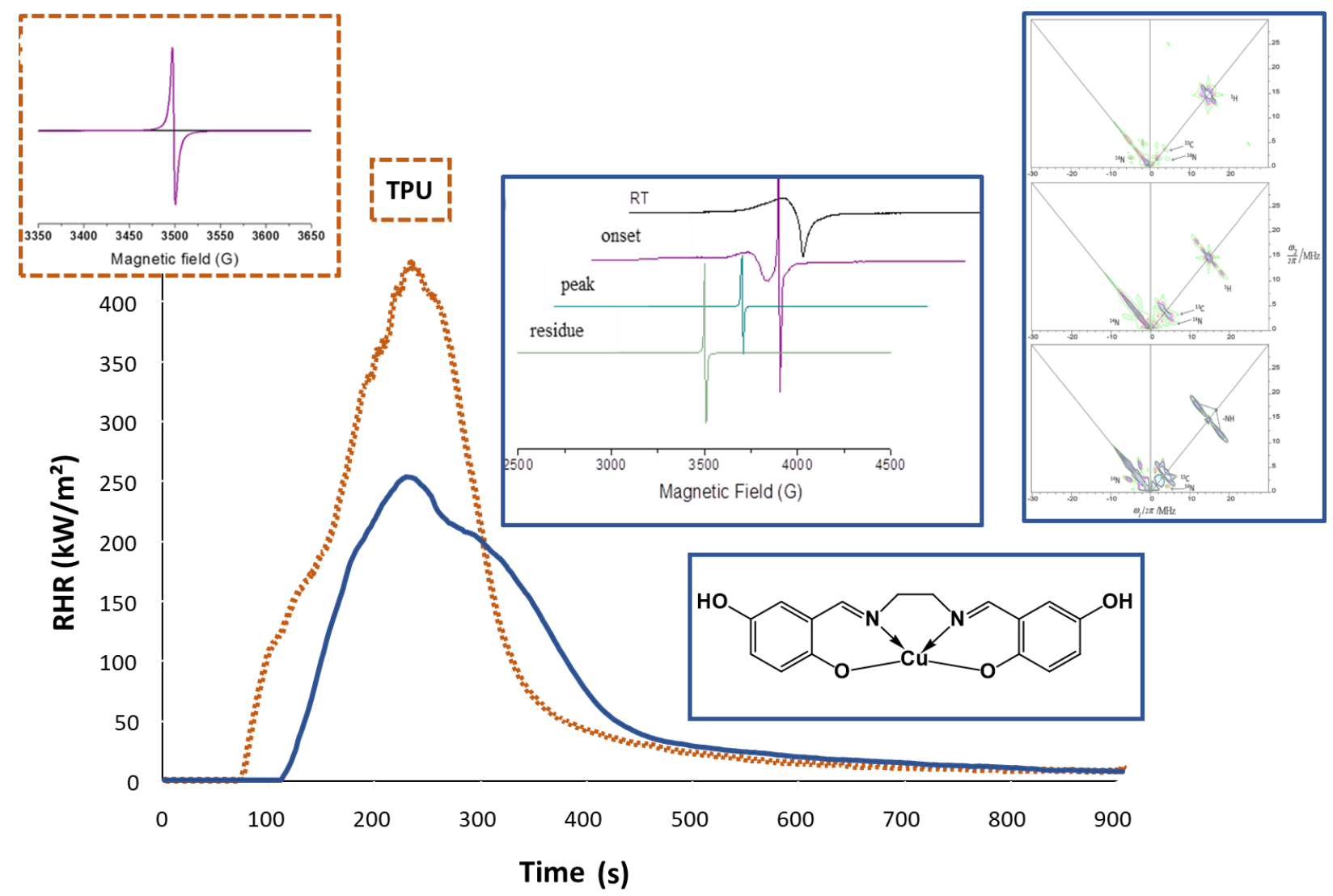




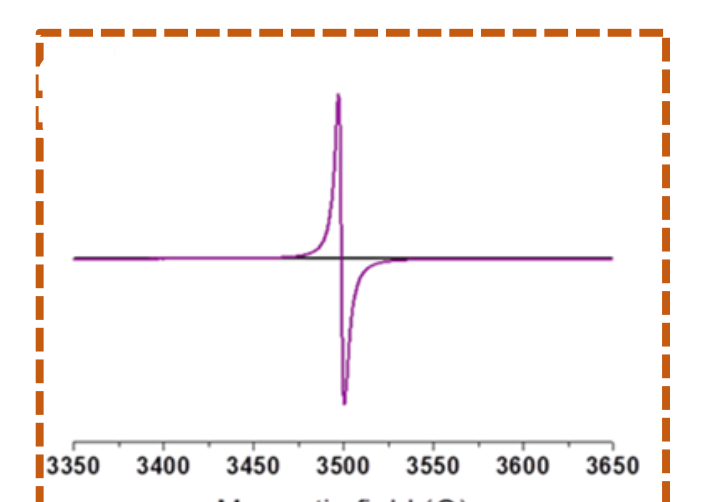

$$
\text { TPU }
$$
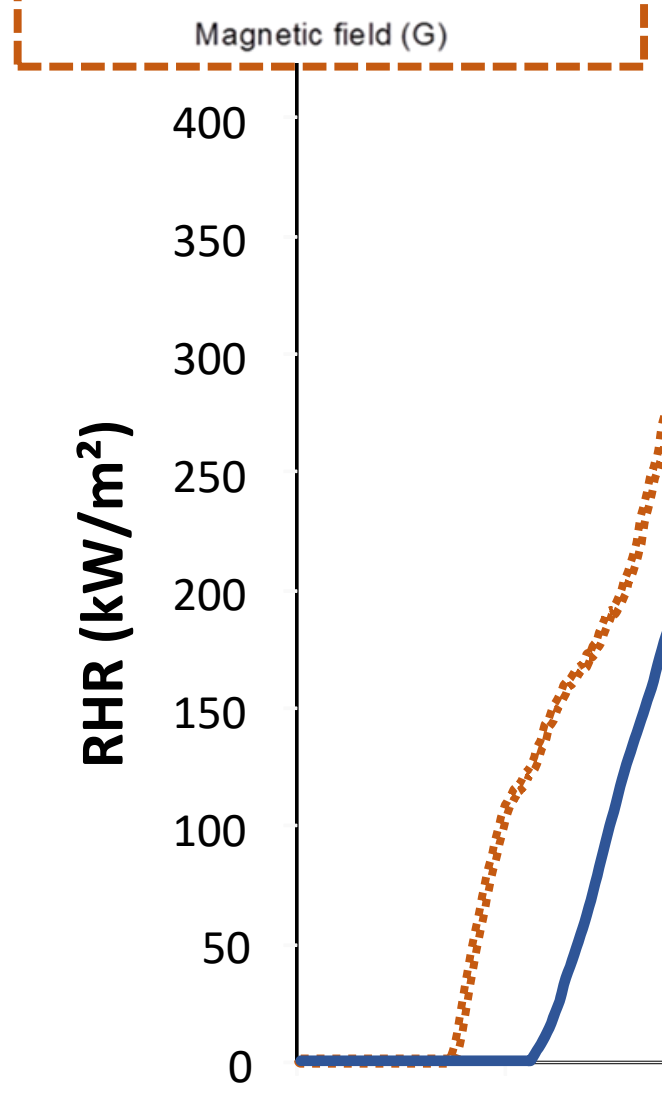

0

100

200

ACS Paragon Plus Environment

Time (s) 